\title{
Advanced Healthcare Materials Controlling Nerve Growth with an Electric Field Induced Indirectly in Transparent Conductive Substrate Materials \\ --Manuscript Draft--
}

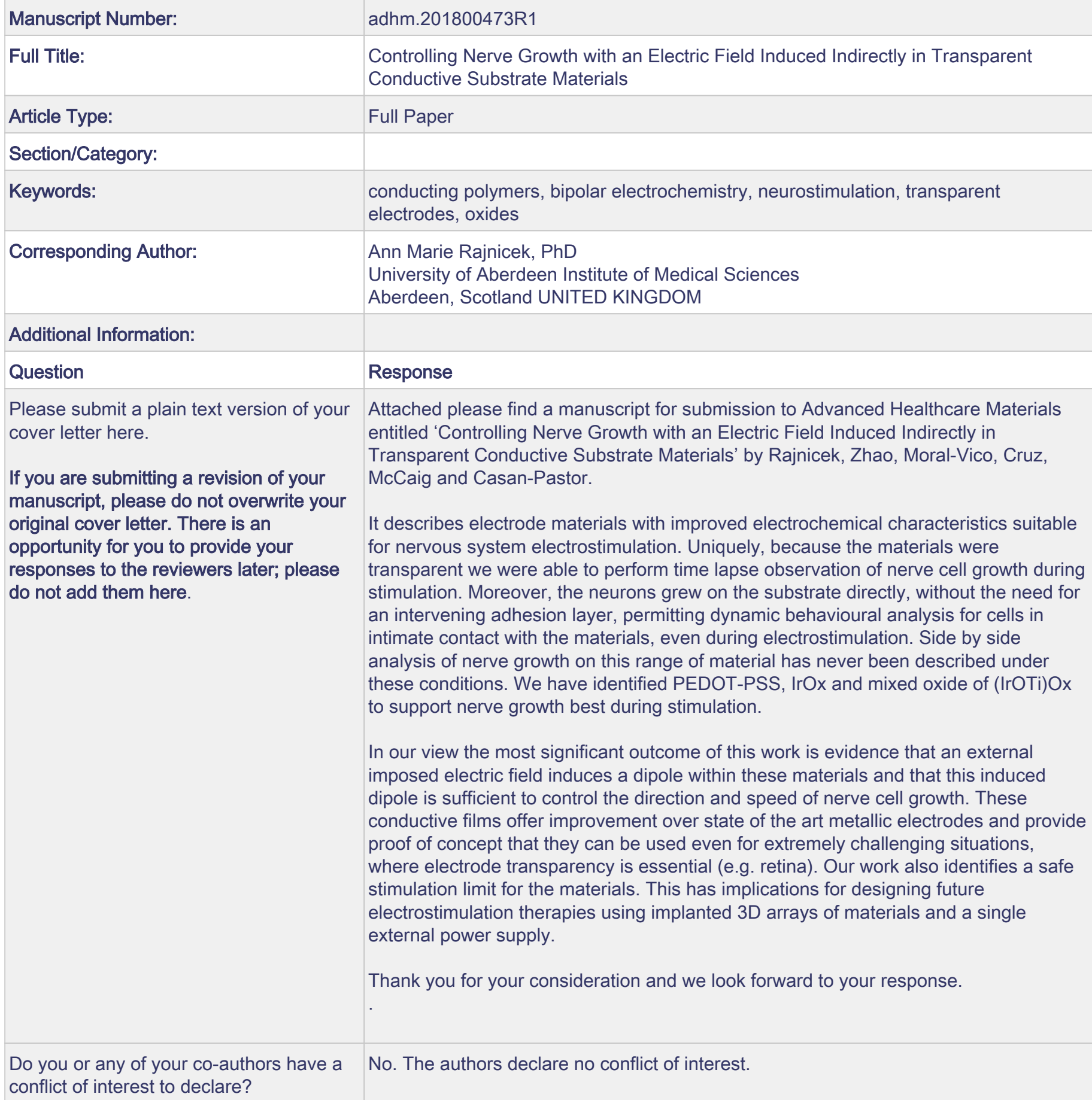

conflict of interest to declare?

Corresponding Author Secondary

Information:

Corresponding Author's Institution:

University of Aberdeen Institute of Medical Sciences

\section{Corresponding Author's Secondary} Institution:

First Author:

Ann Marie Rajnicek, PhD

First Author Secondary Information: 


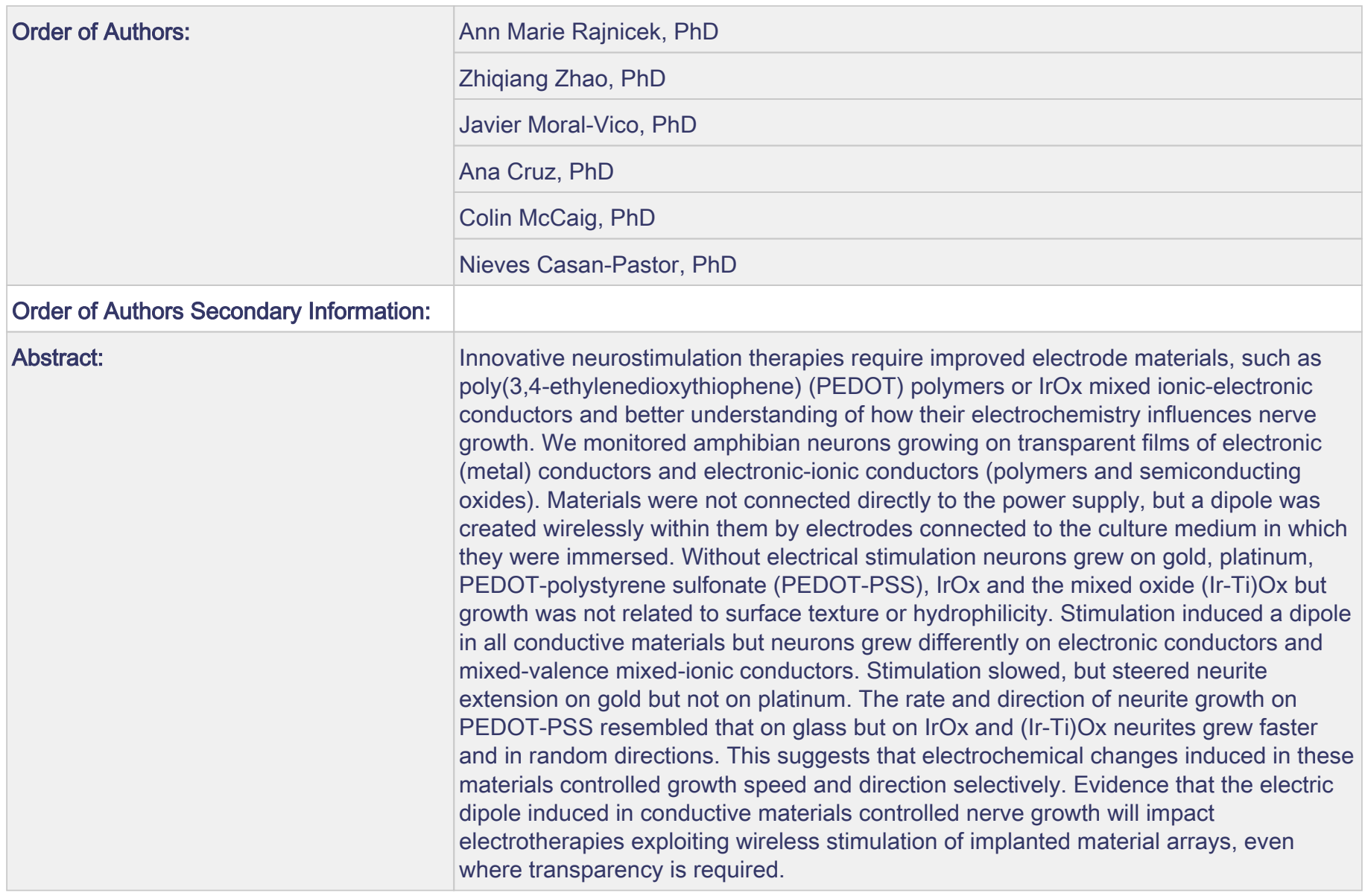




\title{
WILEY-VCH
}

DOI: 10.1002/ adhm.201800473

Article type: Full Paper

\section{Controlling Nerve Growth with an Electric Field Induced Indirectly in Transparent Conductive Substrate Materials}

\author{
Ann M. Rajnicek* ${ }^{1}$, Zhiqiang Zhao ${ }^{1}$, Javier Moral-Vico ${ }^{2}$, Ana M. Cruz ${ }^{2}$, Colin D. McCaig ${ }^{1}$ \\ and Nieves Casañ-Pastor ${ }^{2}$ \\ Dr A. M. Rajnicek, Dr Z. Zhao, Prof C. D. McCaig \\ School of Medicine, Medical Sciences and Nutrition, \\ Institute of Medical Sciences \\ University of Aberdeen \\ Aberdeen, AB25 2ZD \\ United Kingdom \\ E-mail: a.m.rajnicek@abdn.ac.uk \\ Dr. J. Moral-Vico, Dr A. Cruz, Prof N. Casan-Pastor \\ Instituto de Ciencia de Materiales de Barcelona \\ CSIC, Campus de la Universidad Autónoma de Barcelona \\ E-08193 Barcelona \\ Spain \\ E-mail: nieves@icmab.es
}

Keywords: conducting polymers, bipolar electrochemistry, neurostimulation, transparent electrodes, oxides

\begin{abstract}
Innovative neurostimulation therapies require improved electrode materials, such as poly $(3,4-$ ethylenedioxythiophene) (PEDOT) polymers or IrOx mixed ionic-electronic conductors and better understanding of how their electrochemistry influences nerve growth. We monitored amphibian neurons growing on transparent films of electronic (metal) conductors and electronic-ionic conductors (polymers and semiconducting oxides). Materials were not connected directly to the power supply, but a dipole was created wirelessly within them by electrodes connected to the culture medium in which they were immersed. Without electrical stimulation neurons grew on gold, platinum, PEDOT-polystyrene sulfonate (PEDOT-PSS), IrOx and the mixed oxide ( $\mathrm{Ir}-\mathrm{Ti}) \mathrm{Ox}$ but growth was not related to surface texture or hydrophilicity. Stimulation induced a dipole in all conductive materials but neurons grew
\end{abstract}




\section{WILEY-VCH}

differently on electronic conductors and mixed-valence mixed-ionic conductors. Stimulation slowed, but steered neurite extension on gold but not on platinum. The rate and direction of neurite growth on PEDOT-PSS resembled that on glass but on IrOx and (Ir-Ti)Ox neurites grew faster and in random directions. This suggests that electrochemical changes induced in these materials controlled growth speed and direction selectively. Evidence that the electric dipole induced in conductive materials controlled nerve growth will impact electrotherapies exploiting wireless stimulation of implanted material arrays, even where transparency is required.

\section{Introduction}

State-of-the-art microstimulation for spinal cord repair, deep brain stimulation and cochlear implants relies on small implanted metallic capacitative electrodes connected directly to a power source. ${ }^{[1]}$ Although platinum, gold and metal alloys are relatively safe implant materials, adverse reactions may occur at the tissue-material interface when used as electrodes. Unfavourable secondary effects include $\mathrm{pH}$ changes, electrode dissolution, production of $\mathrm{O}_{2}$ gas, $\mathrm{H}_{2}$ gas, free radicals and heat, which can all cause tissue necrosis, highlighting the need for safer alternatives. ${ }^{[2]}$ New candidate materials include intercalation mixed-valence mixed electronic-ionic conducting electrodes, such as iridium oxide (IrOx), or conducting polymers such as polypyrrole (PPy) or Poly(3,4-ethylenedioxythiophene) (PEDOT), which offer faradaic (oxidation-reduction) processes within the material, larger charge injection capacities and lower impedances because the materials undergo redox processes. ${ }^{[3]}$ However, their electrochemical stability, mechanical durability and long-term performance after implantation require further evaluation. ${ }^{[4]}$

A particular challenge for small electrodes is the increase in localized charge density, which amplifies cytotoxic secondary reactions. This can be addressed by using IrOx, conducting polymers (e.g. PEDOT or polypyrrole) and their hybrids, which are mixed valence 


\section{WILEY-VCH}

phases with open structures and valence change capabilities that undergo intercalation or deintercalation of ions through their whole volume, thus increasing charge capacity by one order of magnitude and preventing secondary reactions. ${ }^{[5,6]}$ IrOx-based materials prepared by dynamic electrodeposition offer a wider safe stimulation window than other IrOx materials and compared to metals they increase the effective electrode surface area, reduce its impedance, and increase the stimulation charge capacity tenfold. ${ }^{[5,6]}$ Mammalian neuron growth on IrOx, polypyrrole, and PEDOT conducting polymers prepared with a variety of counterions has been assessed at fixed time points, but not dynamically. ${ }^{[5,7,8]}$

Studies of dynamic neuron growth during external electric field stimulation typically use amphibian (Xenopus laevis) spinal neurons because they are relatively larger, easier to culture, have fewer complications related to sterility, and they grow faster than mammalian neurons. On tissue culture plastic substrates, which are electrically insulating, the growing tips (growth cones) of $X$ laevis neurons exhibit robust responses to external electric fields delivered directly through the culture medium, including growth cones turning to face the cathode, new branches emerging to face the cathode, and faster growth cone migration toward the cathode ${ }^{[9,10]}$ These responses are influenced by the physical and chemical properties of the substratum: in contrast to fast, cathode biased growth on bare plastic (net negative charge), when the substratum was coated with polylysine (net positive charge) growth cones moved slowly and toward the anode. ${ }^{[9]}$ Axons and dendrites of rat hippocampal neurons, which require a polylysine coated substrate for growth, exhibited distinct behaviors. ${ }^{[1,12]}$ Therefore, it is important to understand the interplay between growth surface characteristics, electrochemistry and nerve growth dynamics, especially during stimulation with an external field, which induces electric fields simultaneously within the culture medium and indirectly within the conductive material on which neurons may grow.

By electrochemical principles, hardwired electrodes drive an electric field within an electrolyte solution (e.g. culture medium). When a conducting material is immersed in it a 


\section{WILEY-VCH}

dipole (electrical potential) is induced within the material indirectly; a phenomenon known as 'bipolar electrochemistry' ${ }^{[13]}$ The induced potential, with a polarity opposite to that imposed in the electrolyte medium, starts at the borders between the ionic medium and the material, with concurrent redox reactions induced at the material at sufficiently large potentials. The ability to induce an electric field wirelessly on an implanted conductive material has advantages for electrostimulation therapies but there is poor understanding of the interplay between electrochemical changes in the materials and the consequences for neuron attachment, survival and nerve process outgrowth.

This study is the first to evaluate the dynamic behavior of neurons responding to bipolar electrochemical changes induced in conductive substrates, encompassing metals, polymers and oxides with established electrochemical behaviors. ${ }^{[6,14,15,16]}$ Neurons were plated directly on the materials (no coating), which is distinct from studies in which neuron growth on insulating materials, ${ }^{[16]}$ or polylysine-coated materials was tested, either without an imposed external electric field, ${ }^{[5,7,8,14,17,23]}$ or when the material was connected directly to the power supply. ${ }^{[18,19]}$ At sufficiently high potentials $\mathrm{O}_{2}$ and $\mathrm{H}_{2}$ gas bubbles formed at the edges of the materials, supporting the notion that indirect electrical stimulation produced a dipole within the material layer by bipolar electrochemical principles.

Our data will impact the design of wireless electrostimulation therapies because they show that implantable conductive materials can be tailored to control the speed or direction of nerve outgrowth, they identify a safe potential limit for the materials, and they demonstrate that the principles apply to circumstances requiring electrode transparency (e.g. retina), which are particularly challenging.

\section{Materials and Methods}

\section{Preparation of conductive substrates}

Supporting Information (Table S1) details synthesis of the whole range of conductive substrates but essential details are here. Materials were prepared as transparent (Figure 1) thin 


\section{WILEY-VCH}

films on glass or quartz (Ir-Ti mixed oxides). Milli Q water was used for all solutions. Soda lime glass slides $(25 \mathrm{~mm}$ x $60 \mathrm{~mm}$ ) coated with a $300 \mathrm{~nm}$ layer of indium tin oxide (ITO) were from Solems (catalog number YSUB/ITOSOL). For the electrodeposition of $\mathrm{IrO}_{\mathrm{x}}$ and polymers $24 \mathrm{~mm}$ x $70 \mathrm{~mm}$ soda lime glass slides (AFORA reference KN26X76TB) were coated by thermal evaporation with a $5 \mathrm{~nm}$ adhesion layer of Ti followed by either gold (15 $\mathrm{nm}$ ) or platinum (12 nm); a thickness that ensured transparency (Figure 1).
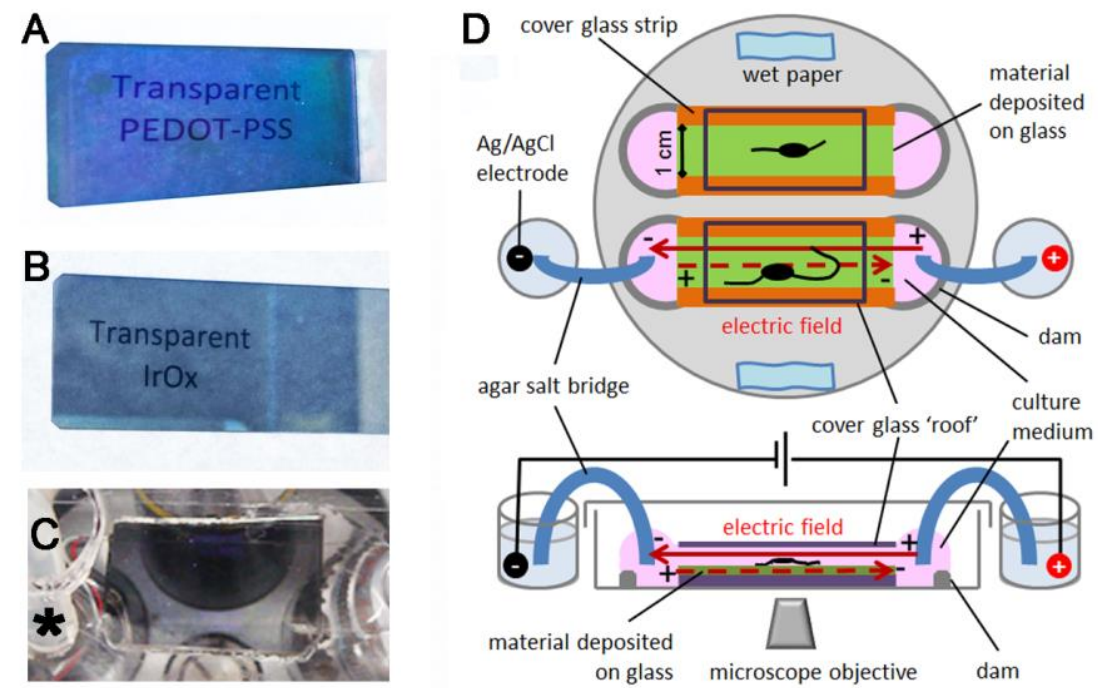

Figure 1. Experimental scheme. A and B) Transparency of materials (blue) electrodeposited onto glass. C) IrOx material during an electric field experiment. The end of an agar bridge is visible (asterisk) and the microscope objective turret can be seen through the material. D) The electric field set up. Control (no electric field) and electric field conditions were run in parallel. Materials were not 'wired' directly to the power supply. Arrows indicate the imposed external electric field (solid red arrow) in the culture medium and the dipole (dotted red arrow) of opposite polarity induced within the materials on which the neurons grew. For some experiments the cells grew directly on the plastic and the materials were

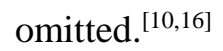

IrOx thin films were prepared using a dynamic electrodeposition procedure modified from previous methods by sweeping from 0 and $0.55 \mathrm{~V}$ vs $\mathrm{Ag} / \mathrm{AgCl}$ during 50 cycles. $^{[6,20,21]}$ 


\section{WILEY-VCH}

Briefly, a final volume of $50 \mathrm{ml}$ of solution ( $\mathrm{pH}$ 10) was prepared by dissolving sequentially, $2 \cdot 10^{-4}$ moles of $\mathrm{IrCl}_{3} . \mathrm{H}_{2} \mathrm{O}$ (Aldrich $99.9 \%$ ), $1 \cdot 10^{-3}$ moles of oxalic acid, $\mathrm{H}_{2} \mathrm{C}_{2} \mathrm{O}_{4} \cdot 2 \mathrm{H}_{2} \mathrm{O}$ (Aldrich 99\%) and 5·10 $0^{-3}$ moles of $\mathrm{K}_{2} \mathrm{CO}_{3}$ (Aldrich, 99\%) in water. The solution was kept at $37^{\circ} \mathrm{C}$ for 4 days and then stored at $4^{\circ} \mathrm{C}$ until use. Electrosynthesis was performed using a VMP potentiostat (Bio-logic) to control electrodeposition. A three-electrode cell system consisted of a Pt counter electrode and a working electrode with the same dimensions and a Pt quasireference electrode with a potential equal to that versus $\mathrm{Ag} / \mathrm{AgCl}$. This pseudo-reference $\mathrm{Pt}$ is stable versus $\mathrm{Ag} / \mathrm{AgCl}$ during $\mathrm{CV}$, possibly due to the formation of an oxide on the surface. ${ }^{[22]}$ Positive and negative electrodes were placed in a parallel arrangement using two Teflon pieces to maintain a distance of $1 \mathrm{~cm}$ between electrodes.

Ir-Ti mixed oxides were prepared on quartz slides (VWR International) following thermal evaporation with a $5 \mathrm{~nm}$ thick Ti adhesion layer and $12 \mathrm{~nm}$ of Pt. (Ir-Ti)Ox films were prepared by spin coating ethanol solutions containing titanium (IV) and iridium (III) salts. ${ }^{[14]}$ The mixed Ir-Ti solution was prepared by mixing equal volumes of Ti and Ir solutions. The $0.21 \mathrm{M}$ titanium solution (50 ml final volume) was formed by dissolving Titanium isopropoxide $\left(\mathrm{Ti}(\mathrm{OiPr})_{4} 99.99 \%\right.$, Aldrich $\left.0.011 \mathrm{M}\right)$ in ethanol in the presence of acetylacetone (99+\%, Aldrich $0.024 \mathrm{M})$ and allowed to age for one day. $0.024 \mathrm{M}$ iridium (III) chloride solutions $\left(1.2 \cdot 10^{-3} \mathrm{M}\right.$ of $\mathrm{IrCl}_{3} \cdot \mathrm{xH}_{2} \mathrm{O} 99.9 \%$, Aldrich) were prepared to achieve mixtures Ir:Ti 1:10 and in $0.048 \mathrm{M}$ concentration to achieve final ratios Ir:Ti 2:10. Both contained acetic acid $\left(\mathrm{CH}_{3} \mathrm{COOH} 99 \%\right.$ Aldrich) in six fold excess with respect to iridium. The solutions were mixed and filtered $(0.2 \mu \mathrm{m})$ prior to spin coating at $3000 \mathrm{rpm}$ using a spin processor (Laurell Technologies Corporation, model WS-400B-6NPP-LITE/8K). Monolayers with a Ir:Ti ratio $1: 10$ were annealed at $600^{\circ} \mathrm{C}$ during $4 \mathrm{hrs}$ or $6 \mathrm{~h}$ and at $650^{\circ} \mathrm{C}$ for 4 or $6 \mathrm{~h}$. Three layer coatings with the Ir:Ti ratio 1:10 and 2:10 were prepared by this procedure and annealed at $600^{\circ} \mathrm{C}$ for $6 \mathrm{~h}$. 


\section{WILEY-VCH}

Materials based on poly(3,4-ethylenedioxythiophene) (PEDOT) were prepared from the monomer 3,4-(ethylenedioxy)thiophene (EDOT) (Sigma-Aldrich, 97\%) stored at $4{ }^{\circ} \mathrm{C}$ until use ${ }^{[8]}$ Before use, the $0.01 \mathrm{M}$ EDOT solution mixed with the different counterions was deoxygenated under argon for 30 minutes. For PEDOT-PSS synthesis the electropolymerization solution contained 0.1 M Poly(3,4-sodium styrene sulfonate) (PSS). PEDOT-PSS films were synthesized in two ways: potentiostatically at $0.9 \mathrm{~V}$ versus reference (PEDOT-PSS, potentiostatic) and galvanostatically with a current of $1.25 \mathrm{~mA}$ (PEDOT-PSS, galvanostatic) using the same type of substrate, electrochemical cell and potentiostat described above for IrOx. The reaction was stopped when charge reached $900 \mathrm{mC} / 10 \mathrm{~cm}^{2}$, for thin samples, and $4000 \mathrm{mC} / 10 \mathrm{~cm}^{2}$ for thick samples.

Before use the materials were rinsed with Milli Q water and allowed to dry. No further surface treatment was performed. The material-coated section of each slide was cut into thirds and pieces were secured (material side up) to both channels of the electric field chamber and neurons were plated onto them directly (Figure 1D).

\section{Assessing properties of the materials}

Sample characterization confirmed previous observations. ${ }^{[6,14,23]}$ Atomic Force Microscopy (AFM) performed in oscillating (tapping) mode characterized the material topography (Agilent Technologies model 5400 Scanning Probe Microscope, analysed with Mountains Map Premium software from Digital Surf Co), which was quantified from measurements of peak to valley distance and mean roughness (deviation with respect to central plane). For each material up to five zones were assessed in the same surface.

The composition of each material was confirmed by grazing angle X-ray-diffraction, X-ray photoelectron spectroscopy (XPS) and infrared analysis (ATR-IR) as described previously. ${ }^{[6,14,23]}$ Hydrophilicity was measured after rinsing the sample with milli Q water, allowing it to dry and placing a $1 \mu \mathrm{l}$ droplet of milli Q water on the sample. The contact angle 


\section{WILEY-VCH}

of the droplet relative to the sample surface was measured using a Pocket PG2 goniometer.

The conductivity and redox characteristics of the materials have been described. ${ }^{[8,6,14,17]}$ Cell culture

Animal procedures were carried out under license in accordance with the United Kingdom Animals (Scientific Procedure) Act 1986 and were approved by the ethics committee of the University of Aberdeen. Embryos and primary cultures of Xenopus laevis spinal neurons were prepared as previously. ${ }^{[9,10]}$ Unless stated otherwise reagents for cell culture were from Sigma. Embryos obtained by in vitro fertilisation were maintained in 5\% DeBoer's solution (5.5 mM NaCl, 0.07 mM KCl, $0.02 \mathrm{mM} \mathrm{CaCl}_{2}, \mathrm{pH}$ 7.2) until Nieuwkoop stage 20-22. Embryos, still in their jelly coats, were immersed briefly in $70 \%$ ethanol to surface sterilise them immediately before dissection and then rinsed sequentially in 5\% DeBoer's solution and then Steinberg's solution. All solutions were filter sterilised for use. The dorsal thirds of embryos were transferred to $1 \mathrm{mg} \mathrm{ml}^{-1}$ type I collagenase in Steinberg's solution $\left(58 \mathrm{mM} \mathrm{NaCl}, 0.67 \mathrm{mM} \mathrm{KCl}, 0.44 \mathrm{mM} \mathrm{Ca}\left(\mathrm{NO}_{3}\right)_{2}, 1.3 \mathrm{mM} \mathrm{MgSO}_{4}, 4.6 \mathrm{mM}\right.$ Trizma Base, $\mathrm{pH}$ 7.9) for neural tube dissection. Neural tubes were disaggregated in $\mathrm{Ca}^{2+}-\mathrm{Mg}^{2+}$-free Steinberg's (58 mM NaCl, 0.67 mM KCl, 4.6 mM Trizma Base, 0.4 mM EDTA, pH 7.9), which was then replaced with culture medium: $20 \%(\mathrm{v} / \mathrm{v})$ modified Leibovitz L-15 medium without L-glutamine (ICN Biomedical), $2 \%(\mathrm{v} / \mathrm{v})$ penicillin $\left(5000 \mathrm{IU} \mathrm{ml}^{-1}\right)$-streptomycin $\left(5000 \mu \mathrm{g} \mathrm{ml}^{-1}\right), 1 \%(\mathrm{v} / \mathrm{v})$ fetal bovine serum, $77 \%(\mathrm{v} / \mathrm{v})$ Steinberg's solution $(\mathrm{pH} 7.9)$ and triturated gently, to yield a plating density of 1.5 neural tubes per channel.

\section{Electric field application}

Electric field chambers were modified Falcon 3003 tissue culture dishes. ${ }^{[10,16]}$ For cells plated on plastic, silicone adhesive (Dow Corning RTV 3140) secured two strips of no. 1 thickness coverglass (64 mm long x $12 \mathrm{~mm}$ wide) $10 \mathrm{~mm}$ apart in parallel to define each channel. Neurons were plated in the area between the strips and covered with a coverglass (64 


\section{WILEY-VCH}

mm x $24 \mathrm{~mm}$ ) secured using silicone compound (Dow Corning DC4), yielding channel dimensions of $64 \mathrm{~mm} \times 10 \mathrm{~mm} \times 0.5 \mathrm{~mm}$.

Modification of this method was used for conductive materials (Figure 1D). The fragment of material coated glass $(\sim 20 \mathrm{~mm}$ x $25 \mathrm{~mm})$ was glued to the dish, material side up. Silicone adhesive (Dow Corning RTV 3140) secured a strip of coverglass (20 mm x 5 mm, no. 1 thickness) to each long edge of the sample, leaving a $10 \mathrm{~mm}$ gap. A third coverglass (20 $\mathrm{mm} \times 20 \mathrm{~mm}$ ) was placed over the cell suspension after plating, secured with silicone grease to create a $20 \mathrm{~mm} \times 10 \mathrm{~mm} \times 0.5 \mathrm{~mm}$ channel.

The electric field was from a DC power supply connected to two $\mathrm{Ag} / \mathrm{AgCl}$ electrodes in baths of Steinberg's solution. Electrical contact to the cell cultures was made through two $2 \% \mathrm{w} / \mathrm{v}$ agar bridges (in Steinberg's solution), with one end of each bridge in the electrode bath and the other end in the pools of culture medium at each end of the channel. Medium was contrained by dams of RTV3140 silicone. The electric field was set by measuring the voltage across the chamber length to yield 50,100 or $150 \mathrm{mV} \mathrm{mm}^{-1}$.

Time lapse analysis of neuron growth

The length of each neurite and the angle of its growth cone (distal tip of neurite) relative to the electric field were determined from phase contrast images captured hourly for 3h using a Zeiss Axiovert 25 microscope and a monochrome CCD camera (Hitachi, Japan) using MetaMorph software (Molecular devices, USA). During electric field stimulation the external cathode was to the left and the external anode was to the right (horizontal field vector) in all mages. Therefore, the angles of growth cone turning relate to the polarity of the external electric field imposed within the culture medium rather than the field induced within the underlying conductive material. Composite drawings (e.g. Fig 4D) were made by hand on acetate sheets to summarise growth responses qualitatively. Cell images were printed at the same scale and the entire path of each neurite was then traced. The centre of the cell body of each neuron was superimposed on a common point and individual neurons were traced, taking 


\section{WILEY-VCH}

care to maintain the horizontal axis, which was parallel to the imposed external electric field vector and therefore, parallel to the induced dipole in the material.

\section{Statistical Analysis}

All growth cones that migrated throughout during the experiment were included in the analysis. Data were not normalised but cell survival was expressed as the percentage of total growth cones that continued to advance during the entire $3 \mathrm{~h}$ and then compared to the relevant substratum-matched control using a D-test. ${ }^{[24]}$ The mean rate of growth cone advance and the mean angle turned by growth cones were compared to (no electric field) controls with an unpaired Student's 2-tailed t test (Excel) with a $\mathrm{P} \leq 0.05$ indicating significance. Data shown are mean \pm SEM unless stated otherwise in the figure. The number of growth cones measured on each material, the number of culture dishes and the number of experimental repeats are indicated in the relevant figures. Cell culture experiments were repeated on at least three different days using different clutches of embryos.

\section{Results}

\section{Neuron growth on materials without an imposed external electric field}

Neuron growth responses for all conditions are summarised in Table 1. Initial experiments determined which of the transparent films supported neuron outgrowth without any imposed electric stimulation. Assessment on the complete set of 16 materials prepared is summarised in the Supporting Information (Figure S1, Figure S2) and data from the six best performing materials are presented in the main text (Figure 2). These include metals (platinum and gold), conductive polymers (PEDOT) and semiconducting oxides (IrOx and (Ir-Ti)Ox). About $6 \mathrm{~h}$ after plating directly onto glass and without an imposed field there were 24 growth cones per dish (Figure 2A) but there were significantly more on gold, PEDOT-PSS, (Ir-Ti)Ox and platinum. Gold performed best, with six times more growth cones per dish than glass and on PEDOT-PSS (prepared either by galvanostatic or potentiostatic methods) there 
Table 1. Qualitative summary of neuron growth on materials compared to glass

\begin{tabular}{|c|c|c|c|c|c|}
\hline Material & Sprouting $^{\mathrm{a}}$ & Electric field $^{\mathrm{b}}$ & \multicolumn{3}{|c|}{ Dynamic behavior } \\
\hline & $\begin{array}{c}\text { Growth cones } \\
\text { dish }^{-1}\end{array}$ & & $\begin{array}{l}\text { Sustained } \\
\text { migration }^{\mathrm{c}}\end{array}$ & $\begin{array}{l}\text { Migration } \\
\text { speed }^{\mathrm{c}}\end{array}$ & $\begin{array}{l}\text { Directed to } \\
\text { cathode }^{\mathrm{d}}\end{array}$ \\
\hline \multirow[t]{2}{*}{ platinum } & $\leftrightarrow$ & no & $\uparrow$ & $\leftrightarrow$ & \\
\hline & & yes & $\leftrightarrow$ & $\leftrightarrow$ & $\leftrightarrow$ \\
\hline \multirow[t]{2}{*}{ gold } & $\uparrow$ & no & $\leftrightarrow$ & $\uparrow$ & \\
\hline & & yes & $\downarrow$ & $\leftrightarrow$ & $\uparrow$ \\
\hline \multirow{2}{*}{$\begin{array}{l}\text { PEDOT-PSS } \\
\text { (potentiostatic) }\end{array}$} & $\uparrow$ & no & $\leftrightarrow$ & $\uparrow$ & \\
\hline & & yes & $\downarrow$ & $\leftrightarrow$ & $\uparrow$ \\
\hline \multirow{2}{*}{$\begin{array}{l}\text { PEDOT-PSS } \\
\text { (galvanostatic) }\end{array}$} & $\uparrow$ & no & $\uparrow$ & $\uparrow$ & \\
\hline & & yes & $\downarrow$ & $\leftrightarrow$ & $\uparrow$ \\
\hline \multirow[t]{2}{*}{$\mathrm{IrOx}$} & $\leftrightarrow$ & no & $\leftrightarrow$ & $\uparrow$ & \\
\hline & & yes & $\downarrow$ & $\uparrow$ & $\leftrightarrow$ \\
\hline \multirow[t]{2}{*}{$(\mathrm{Ir}-\mathrm{Ti}) \mathrm{Ox}$} & $\uparrow$ & no & $\leftrightarrow$ & $\uparrow$ & \\
\hline & & yes & $\leftrightarrow$ & $\uparrow$ & $\leftrightarrow$ \\
\hline
\end{tabular}

Key: $\uparrow$ significantly better; $\downarrow$ significantly worse; $\leftrightarrow$ no change.

${ }^{a}$ Sprouting was quantified only for no electric field conditions and compared to glass.

b) External imposed field $50 \mathrm{mV} \mathrm{mm}^{-1}$. ${ }^{\mathrm{c})}$ Compared to responses on glass without, and with electric fields, respectively. ${ }^{\text {d) }}$ Compared to glass during electric field stimulation.

The influence of each material was quantified further by calculating the percentage of growth cones that advanced continuously throughout the experiment and their migration speed (Figures 2B,2C). On glass 36\% of the growth cones advanced, migrating at $9.3 \pm 0.9$ $\mu \mathrm{m} \mathrm{h}^{-1}$. The values for gold or PEDOT-PSS(potentiostatic) were similar to glass but they were faster on PEDOT-PSS(galvanostatic). When compared to glass, PEDOT-PSS(galvanostatic) was the only material that improved neurite sprouting, sustained migration and the rate of growth cone advance collectively (Figure 2, Table 1). With the exception of platinum each 


\section{WILEY-VCH}

material increased the rate of growth cone migration (Figure 2C) compared to glass, with fastest migration on $\mathrm{IrOx}\left(21.4 \pm 1.3 \mu \mathrm{m} \mathrm{h}^{-1}\right)$.

\section{Physical traits of favoured materials}

Because gold, IrOx and PEDOT-PSS(potentiostatic and galvanotatic) supported neurite growth better than glass we compared their surface characteristics to identify traits that favoured growth. Atomic force microscopy revealed that the surface textures of the gold and (Ir-Ti)Ox films were smoother than glass but IrOx and PEDOT-PSS surfaces were rougher (Figure 3). There was no correlation between neurite growth and surface roughness. IrOx and PEDOT-PSS, which are rougher than glass, each increased neurite growth rates, but so did gold, which is smoother than glass. Similarly, the smoothest surface (gold) supported neuronal differentiation best (growth cones per dish) but the roughest (PEDOT-PSS) surfaces also improved it (Figure 2A).

The relative hydrophilicity of the materials was determined from contact angle measurements, with largest values indicating lowest hydrophilicity. All materials that supported growth were less hydrophilic than glass. Ranked with increasing hydrophilicity: (IrTi)Ox $<$ PEDOT-PSS $($ potentiostatic $)=$ IrOx $<$ PEDOT PSS $($ galvanostatic $)<$ gold $<<$ glass (Figure 3D). The hydrophilicity of gold surfaces has been controversial. Our data support the idea that during exposure to air bound oxygen renders gold less hydrophilic. ${ }^{[25]}$ Here, neuron outgrowth was supported best by surfaces with intermediate hydrophilicity. The contact angle $(60 \pm 8.6 ; \mathrm{n}=11)$ for Falcon tissue culture plastic, which supports growth better than glass, is similar to angles for PEDOT and IrOx.

\section{Neurite growth on an insulating (plastic) substrate}

The dynamic behavior of $X$ laevis neurites growing on an insulating material (tissue culture plastic) was quantified during electric field exposure for comparison to conductive substrates. Such studies typically use $150 \mathrm{mV} \mathrm{mm}^{-1},{ }^{[10,16]}$ which resembles the natural electric 


\section{WILEY-VCH}

field in the developing $X$ laevis spinal cord, ${ }^{[26]}$ but we also defined responses at 50, 100 and $150 \mathrm{mV} \mathrm{mm}^{-1}$.

In the absence of an electric field neurites advanced in random directions, but in fields of 50,100 or $150 \mathrm{mV} \mathrm{mm}^{-1}$ they turned toward the cathode (Figure 4). This was quantified for individual growth cones by measuring their change in growth direction and their migration rate. Without an electric field growth cones changed direction by $1 \pm 3$ degrees (zero is random). However, during exposure to fields of 50,100 or $150 \mathrm{mV} \mathrm{mm}^{-1}$ growth cones turned increasingly toward the cathode (indicated by negative angles) by $-8 \pm 2,-19 \pm 2$, and $-42 \pm 3$ degrees, respectively (Figure 4A). Compared to no electric field controls $\left(20 \pm 1 \mu \mathrm{m} \mathrm{h}^{-1}\right)$ growth cones migrated faster in fields of $100 \mathrm{mV} \mathrm{mm}^{-1}$ or $150 \mathrm{mV} \mathrm{mm}^{-1}\left(27 \pm 1 \mu \mathrm{m} \mathrm{h}^{-1}\right.$ and $34 \pm 1 \mu \mathrm{m} \mathrm{h}^{-1} ; p<0.005$ each) but not at $50 \mathrm{mV} \mathrm{mm}^{-1}\left(22 \pm 1 \mu \mathrm{m} \mathrm{h}^{-1}\right)$ (Fig. 4B).

\section{Evidence for induction of an electrical dipole in materials}

Neuron growth on conductive materials was quantified under conditions where the electric field was delivered by electrodes immersed in saline baths connected by agar-salt bridges to pools of culture medium at each edge of the neuron-seeded materials. Consequently, a uniform electric field was imposed in the culture medium bathing the cells, and simultaneously, an indirect electric dipole of opposite polarity was hypothesised within the conductive film on which the cells grew (Figure 1, Figure 5).

During exposure to fields larger than $50 \mathrm{mV} \mathrm{mm}^{-1}$ changes observed in the culture medium, and in the conductive films themselves confirmed the existence of a dipole within the material. Some materials subjected to high potentials (fields $>50 \mathrm{mV} \mathrm{mm}^{-1}$ ) generated bubbles at the material edges, with $\mathrm{pH}$ increase at the induced cathode margin (Figure 5). These changes did not occur on (insulating) glass or plastic substrates, even at $150 \mathrm{mV} \mathrm{mm}^{-1}$, suggesting that they arise from electrochemical processes induced in the conductive films.

High electric fields had detrimental effects on the integrity of some coatings. At low potentials $\left(\leq 50 \mathrm{mV} \mathrm{mm}^{-1}\right)$ the gold substrate and its underlying titanium adhesion layers 


\section{WILEY-VCH}

remained intact but at higher potentials $\left(100\right.$ or $\left.150 \mathrm{mV} \mathrm{mm}^{-1}\right)$ the gold layer delaminated, beginning at the induced anode, with a distinct front that receded from that edge as the experiment proceeded (Figure 5). This did not occur for pure gold films with no underlying titanium, supporting the idea that an electric field was induced within the material itself. Consequently, in subsequent experiments the electric field was restricted to $50 \mathrm{mV} \mathrm{mm}^{-1}$, at which there were no significant $\mathrm{pH}$ changes in the medium and materials remained intact, even upon microscopic inspection.

\section{Growth cone behavior on conductive substrates during electrical stimulation}

The materials were deliberately prepared as transparent films to permit observation of dynamic growth cone behavior. Table 1 is a qualitative summary of the growth responses with and without external electric field stimulation. The polarities described refer to the electric field imposed in the medium. As expected, growth cones migrated in random directions on glass without stimulation but after $3 \mathrm{~h}$ in an electric field of $50 \mathrm{mV} \mathrm{mm}^{-1}$ the growth cones had turned toward the cathode to the same extent $(-5 \pm 2 \mathrm{deg}, \mathrm{n}=61)$ as those on plastic $(-8 \pm 2$ deg, $\mathrm{n}=242 ; p>0.05$ ) (Figure 4 and Figure 7). Although this low field did not increase growth cone migration speed on plastic (Figure 4B), growth on glass was faster with stimulation $\left(12.2 \pm 1.2 \mu \mathrm{m} \mathrm{h}^{-1}, \mathrm{n}=61\right)$ than without it $\left(9.3 \pm 0.9 \mu \mathrm{m} \mathrm{h}^{-1}, \mathrm{n}=44 ; \mathrm{p}<0.05\right)$. The percentage of growth cones on platinum and (Ir-Ti)Ox substrates that advanced continuously during the entire $3 \mathrm{~h}$ experiment was similar to glass but was less on all other materials (Figure 6A). The speed of growth cone migration was similar for glass, platinum, gold and PEDOT-PSS materials, but growth cones on IrOx and (Ir-Ti)Ox migrated faster (Figure 6B). Neurons growing on gold or platinum behaved differently during $50 \mathrm{mV} \mathrm{mm} \mathrm{m}^{-1}$ electric field exposure. Neurite growth on gold was biased toward the cathode, with significant turning evident within the first hour and by 3 hours growth cones had turned 3 fold more $(-15$ $\pm 3 \mathrm{deg})$ toward the cathode than those on glass $(-5 \pm 2 \mathrm{deg} ; \mathrm{p}<0.05)$ (Figure 7A). Whereas electrical stimulation increased the migration speed for growth cones on glass (Figure 4B), 


\section{WILEY-VCH}

those on gold advanced more slowly with stimulation $\left(9.6 \pm 0.9 \mu \mathrm{m} \mathrm{h}^{-1}, \mathrm{n}=78\right)$ than without it $\left(15.5 \pm 1.4 \mu \mathrm{m} \mathrm{h}^{-1}, \mathrm{n}=73 ; \mathrm{P}<0.01\right)$ and fewer advanced continuously during field exposure than without it (Figure 6A). However, upon field exposure the speeds of growth cone advance on gold and glass were similar (Figure 6B), suggesting that those growth cones with persistent migration on gold advanced at least as well as those on glass. During electric field exposure growth cones on platinum migrated at the same speed $\left(11.2 \pm 0.8 \mu \mathrm{m} \mathrm{h}^{-1}\right)$ and turned toward the cathode to the same extent $(-10.9 \pm 3.3, \mathrm{n}=64)$ as those on glass. Similarly, the proportion of growth cones that continued to grow throughout the experiment was identical to that on glass (Figure 6A). Collectively, this indicates that platinum and gold support growth differently during electric stimulation; with better neurite extension on platinum and better directional (cathode) growth on gold.

Dynamic growth cone behaviors on semiconducting IrOx and mixed (Ir-Ti)Ox materials were similar during $50 \mathrm{mV} \mathrm{mm}^{-1}$ external electric field exposure. On IrOx and (IrTi)Ox substrates growth cones migrated faster than on glass, with and without electric field stimulation (Figure 6B and Figure 2C). Migration speeds of growth cones on $\mathrm{IrOx}(20.2 \pm 1.2$ $\left.\mu \mathrm{m} \mathrm{h}^{-1}, \mathrm{n}=69\right)$ and (Ir-Ti)Ox $\left(16.9 \pm 0.9 \mu \mathrm{m} \mathrm{h}^{-1}, \mathrm{n}=83\right)$ were not affected by electric field stimulation $\left(15.4 \pm 2.3 \mu \mathrm{m} \mathrm{h}^{-1}, \mathrm{n}=24 ; 16.8 \pm 1.5 \mu \mathrm{m} \mathrm{h}^{-1}, \mathrm{n}=38\right.$, respectively). Compared to neurons on glass, fewer growth cones on IrOx sustained growth throughout field exposure but on (Ir-Ti)Ox the field did not affect sustained growth (Figure 6B). The direction of neurite growth was not influenced by the electric field on IrOx or (Ir-Ti)Ox (Figure 7A). Collectively, the data indicate that $\mathrm{IrOx}$ and (Ir-Ti)Ox each support nerve growth during electric field stimulation better than glass or metallic (gold or platinum) substrates but that the field does not steer the path of growth cone advance.

On conductive PEDOT-PSS (potentiostatic and galvanostatic) polymer films fewer growth cones advanced continuously throughout electric field exposure than on glass (Figure 6A) but growth was directed toward the cathode more on PEDOT-PSS (Figure 7). Growth 


\section{WILEY-VCH}

cones turned $-16 \pm 4$ degrees $(n=42)$ on PEDOT-PSS (potentiostatic) and $-25 \pm 7$ degrees $(n$ = 32) on PEDOT-PSS(galvanostatic) toward the cathode but the time courses differed. On PEDOT-PSS(potentiostatic) significant cathodal turning occurred within an hour of electric field initiation, but on PEDOT-PSS(galvanostatic) this was not significant until the second hour, with most turning occurring between the second and third hours. The rate of growth cone advance was not affected by the electric field on either PEDOT-PSS material $(12.9 \pm 1.0$ $\mu \mathrm{m} \mathrm{h}^{-1}, \mathrm{n}=42$, potentiostatic; $12.4 \pm 1.2 \mu \mathrm{m} \mathrm{h}^{-1}, \mathrm{n}=32$ galvanostatic) when compared to material-matched, no electric field controls $\left(14.1 \pm 0.9 \mu \mathrm{m} \mathrm{h}^{-1}, \mathrm{n}=75\right.$ potentiostatic; $13.3 \pm$ $\left.0.7 \mu \mathrm{m} \mathrm{h}^{-1}, \mathrm{n}=136\right)$. The robust growth during electric field stimulation and the strong cathodal orientation responses suggest that these materials would be good candidates for indwelling electrodes.

\section{Discussion}

Innovative electrotherapies demand electrodes that permit long term, intimate neuronelectrode association. The need for material transparency presents additional challenges for some applications (e.g. retina). State-of-the-art metallic electrodes require direct connection to a power source and can also induce harmful secondary effects during stimulation. Our aim was to identify electrically conductive materials with improved properties that support neuron growth during electrical stimulation and that can also achieve an electric dipole without a directly wired connection. We coupled the synthesis of transparent, thin, conductive substrates, with a culture model that permits direct observation of neuron growth during stimulation. ${ }^{[10]}$ These time lapse experiments offer advantages, including direct observation of differentiation, survival and neurite outgrowth for neurons in intimate contact with conductive substrates, and microscopic assessment of the material integrity. Unlike mammalian neurons, which require cell attachment factors, $X$ laevis neurons grow on uncoated surfaces, allowing direct assessment of the neuron-material interaction. 


\section{WILEY-VCH}

Electrophysiological recordings have been made from live neurons on transparent

electrodes, and cell growth has been assessed at discrete endpoints from fixed neurons or neuronal stem cell lines but this is the first study of the dynamic behavior of neurons growing directly on (uncoated) conductive substrates during electric field stimulation. ${ }^{[27]}$ Our study differs from previous reports in which materials were hardwired to the power source. ${ }^{[18,19]} \mathrm{We}$ demonstrate for the first time that an electric dipole is induced in the materials without direct connection to a power supply and that it is sufficient to control neuron growth, with different materials triggering different growth responses. These properties can be exploited to deliver electrostimulation indirectly with implanted material arrays, even when transparency is desired, opening exciting possibilities for innovative clinical therapies.

Neurons grew well on films of gold PEDOT-PSS, IrOx, platinum, and (Ir-Ti)Ox without external electrical stimulation. The ability of these diverse materials to support growth despite differences in surface roughness is consistent with reports for $\mathrm{TiO}_{2}$ and $\mathrm{IrOx}$ based materials, where surface chemistry, rather than texture, was key for neuron growth. ${ }^{[6,17]}$ We found no direct correlation between neuron growth and surface hydrophilicity, suggesting that some other aspect of surface chemistry dominated. Failure to grow on ITO (Supplemental Information, Figures S1 and S2) was unexpected because transparent ITO films have been used as recording electrodes for mammalian neurons in vitro ${ }^{[28]}$ However, there ITO was coated with an attachment factor to support mammalian neuron growth but here it was uncoated, suggesting that the surface chemistry of pristine ITO was incompatible with neuron growth.

A limitation of existing indwelling stimulating electrodes is that they are hardwired to a power source. In principle, this can be overcome by inducing an electric dipole in conductive implanted materials remotely (wirelessly). This emerging concept, called bipolar electrochemistry, has important practical implications but is largely unappreciated by biologists. ${ }^{[13,29]}$ Electrodes wired to a power source deliver a potential to an electrolyte 


\section{WILEY-VCH}

solution (e.g. culture medium or body fluid) in contact with the conductive material. The electrochemical consequence is the creation of an anode and cathode at the material and consequent faradaic reactions, with the induced dipole having the opposite polarity to the field imposed in the electrolyte (Figure 5). Several observations indicated that these reactions occurred in our materials: above a threshold potential the material delamination proceeded with a front moving toward the centre of the material, electrolysis bubbles formed at the material poles, and the $\mathrm{pH}$ increased at the induced cathode (and decreased at the anode).

We demonstrate here for the first time that the dipole induced within the material was sufficient to control neuron growth, with distinct responses on different materials. This may be attributable to competition between the opposing polarities of the imposed electric field in the culture medium and the induced dipole in the material; or to the influence of varied surface charge and substratum adhesivity, ${ }^{[9]}$ but we propose that it relates to the varied electrochemistries of materials during stimulation. In metals (gold and platinum) hydrolytic $\mathrm{O}_{2}$ and $\mathrm{H}_{2}$ gas production would occur at certain potentials, in mixed valence systems (IrOx, PEDOT) cation intercalation (negative pole) and deintercalation (positive pole) would also occur, creating an ionic gradient within the material (Figure 5), and in titanium $\mathrm{TiO}_{2}$ may form (with delamination). Simultaneously, ionic gradients of opposing polarity would form in the electrolyte very near the material-electrolyte interface. Intercalation processes have lower potentials than hydrolytic reactions, and with a three electrode configuration and an electric field similar to that used here we measured oxidation potentials versus reference at $0.4 \mathrm{~V}$ for IrOx, at 0.6 to $0.8 \mathrm{~V}$ for gold and at $0.8 \mathrm{~V}$ for PEDOT-PSS. ${ }^{[6,8,14,23]}$ The ionic gradients may therefore explain the observed differences in cell behaviour. The dipole in PEDOT-PSS materials influenced the direction (not speed) of neurite advance but in $\mathrm{IrOx}$ and (Ir-Ti-)Ox it increased the speed (not direction) of growth, suggesting targeted clinical uses for the materials. IrOx coatings are particularly attractive because they are reproducible and IrOxbased materials supported growth well with and without electrical stimulation. We recently 


\section{WILEY-VCH}

developed hybrid materials based on IrOx and carbon nanotubes or graphene that offer promise for nervous system repair based on in vitro experiments using a mammalian nervous system wound model and direct electric stimulation (wired to power supply). ${ }^{[18,37,38]}$

Metallic substrates of gold and platinum supported growth well, even during electrical stimulation, provided a low potential was used. This was not surprising given the established use of these metals as electrodes and the known adverse consequences of using metallic stimulation electrodes at high potentials, but our data indicate a safe limit for their use $(\leq 50$ $\mathrm{mV} \mathrm{mm}^{-1}$ ) to prevent delamination (Figure 5) and tissue necrosis. The distinct neuron behaviors during stimulation on gold and platinum were unexpected. The direction of neurite growth was steered by the electric field on glass but not on platinum (Figure 7). Our work therefore suggests new therapeutic possibilities, stimulating implanted gold arrays remotely to steer nerve growth, without a directly wired connection.

To avoid the limitations of noble metals we assessed metal oxides and conducting polymers. IrOx in pure form or as part of a nanocarbon hybrid (coated with polylysine), which supports mammalian neuron growth has superior faradaic (pseudo-capacitive) chargeinjection properties. ${ }^{[6,31]}$ XPS analysis indicated that the amount of oxygen bound to gold surfaces changes during electric stimulation. The growth promoting properties of gold and IrOx may be related to a similar surface electrochemistry because they are both based on noble metals and both have oxide-like chemistries. However, not all oxides support growth, emphasising the particular benefit of $\mathrm{IrOx}$. Although disks of pristine $\mathrm{TiO}_{2}$ (rutile) supported $X$ laevis neuron growth during stimulation at $150 \mathrm{mV} \mathrm{mm}^{-1}$, X laevis neurons did not grow on pristine films of $\mathrm{TiO}_{2}$ (anatase), even without stimulation (Supporting Information, Figures $\mathrm{S} 1$ and S2). ${ }^{[16]}$ Since they grew well on IrOx during stimulation we prepared composites of Ir-Ti in differing ratios (Supporting Information Table S1). Mixed (Ir-Ti)Ox oxides performed well, but changing the ratio of Ir:Ti from 1:10 (Ir-Ti)Ox to 2:10 (Ir-Ti)Ox improved growth. 


\section{WILEY-VCH}

Grazing angle diffraction analysis of Ir-Ti mixed oxides showed a graded composition, with

more IrOx near the surface, meaning the surface would resemble IrOx. ${ }^{[14]}$

Inherently conducting polymer films, such as polypyrrole (PPY) and PEDOT, are promising materials because they promote neuron growth during electrical stimulation, they can be functionalised for spatially and temporally controlled delivery of growth promoting compounds for nervous system repair, and PEDOT can be synthesised in the nervous system in vivo. ${ }^{[32]}$ Materials were deposited in a thin layer to allow live cell imaging, but this limited the global charge capacity and restricted the upper level of safe electrical stimulation. Low potentials $\left(50 \mathrm{mV} \mathrm{mm}^{-1}\right)$ had no apparent effect on material integrity and neurons grew on gold, PEDOT-PSS, IrOx and (Ir-Ti)Ox, but at higher electric fields (100 or $150 \mathrm{mV} \mathrm{mm}^{-1}$ ) growth was generally poor, with some materials delaminating from the glass support or the underlying titanium adhesion layer. We suggest that at low potentials redox changes were induced by faradaic processes only at the extremes of the induced dipole, but at higher potentials the changes gradually proceeded beyond these margins, oxidizing the underlying adhesion layer (Figure 5). Our two electrode set up for low potential stimulation required 1.0 $\mathrm{V}$ across the sample, which might exceed the oxidation potential of some materials. Here, we may have changed the oxidation state of all materials, with corresponding intercalation of ions (Figure 5), even at low potentials but only higher potentials $\geq 2.0 \mathrm{~V}$ were sufficient to oxidize both the material and the adjacent water, yielding oxygen radical formation, $\mathrm{H}_{2}$ and $\mathrm{O}_{2}$ gas production, $\mathrm{pH}$ changes and delamination of the underlying titanium support layer (Figure 5).

\section{Conclusion: implications for implant materials}

Our data demonstrate for the first time that thin conductive, transparent, materials can deliver electrical stimulation wirelessly to neurons and suggest a safe potential limit for stimulation. Different materials yield different neuron growth responses, which may relate to the material's surface chemistry and conductive properties, suggesting that they can be tuned for specific purposes. The ability to implant 3D arrays of materials will open exciting new 


\section{WILEY-VCH}

possibilities to stimulate multiple electrode arrays remotely using a single external power source.

\section{Supporting Information}

Supporting Information is available from the Wiley Online Library or from the author.

\section{Acknowledgements}

Work was funded by the European Commission FP6 NEST Program (Contract 028473), MAT2011-24363, MAT2015- -65192-R from the Spanish Science Ministry, and La Marato de TV3 Foundation (Identification Number 110131) and Severo Ochoa Programme for Centres of Excellence in R\&D (SEV- 2015-0496).

Author contributions: NC-P, AMR and CDM conceived and designed the study. N-CP, JM-V and AMC prepared the substrate materials and conducted electrochemical and AFM analysis. ZZ performed time lapse nerve growth experiments and analysis under AMR's supervision. AMR, NC-P drafted the manuscript from an early draft prepared by ZZ. All authors participated in refining drafts. Equal contribution from University of Aberdeen and Institut de Ciència de Materials de Barcelona-CSIC.

Received: ((will be filled in by the editorial staff))

Revised: ((will be filled in by the editorial staff)) Published online: ((will be filled in by the editorial staff))

\section{References}

[1] a) S. Shapiro, R. B. Borgens, R. Pascuzzi, K. Roos, M. Groff, S. Purvines, R. B. Rodgers, S. Hagy, P. Nelson, J Neurosurg Spine 2005, 2, 3; b) S. Harkema, Y. Gerasimenko, J. Hodes, J. Burdick, C. Angeli, Y. Chen, C. Ferreira, A. Willhite, E. Rejc, R. G. Grossman, V. R. Edgerton, The Lancet 2011, 377, 1938; c) C. A. Angeli, V. R. Edgerton, Y. P. Gerasimenko, S. J. Harkema, Brain 2014, 137, 1394; d) A. A Fomani, R. R. Mansour, C. M. Florez-Quenguan P. L. Carlen, J Microelectromech Systems 2011, 20, 1109; e) B. J. Allitt, S. J. Morgan, S. Bell, D. A. X. Nayagam, B. Arhatari, G. M. Clark, A. G. Paolini, Hearing Res 2012, 287, 30.

[2] a) S. B. Brummer, M. J. Turner, Bioelectrochem Bioenerg 1975, 2, 13; b) D. R. Merrill, M. Bikson, J. G. R. Jefferys, J Neurosci Methods 2005, 141, 171; c) S. F. Cogan, Annu Rev Biomed Eng 2008, 10, 275. 


\section{WILEY-VCH}

[3] a) S. F. Cogan, Annu Rev Biomed Eng 2008, 10, 275; b) S. J. Wilks, S. M. RichardsonBurns, J. L. Hendricks, D. C. Martin, K. J. Otto, Front Neuroeng 2009, 2,7.

doi:10.3389/neuro.16.007.2009; b) S. Venkatraman, J. Hendricks, Z. A. King, A. J. Sereno, S. Richardson-Burns, D. Martin, J. M. Carmena, Neural Systems and Rehabilitation Engineering, IEEE Transactions 2011, 19, 307; c) A. M. Cruz, L. Abad, N. M. Carretero, F. J. Moral-Vico, P. Lozano, G. Subias, V. Padial, M. Carballo, J. E. Collazos-Castro, N. Casañ-Pastor, J Phys Chem C 2012, 116, 5155.

[4] T. Boretius, M. Schuettler, T Steiglitz, Artificial Organs 2011, 35, 245.

[5] S. F. Cogan, Annu Rev Biomed Eng 2008, 10, 275.

[6] A. M. Cruz, L. Abad, N. M. Carretero, F. J. Moral-Vico, P. Lozano, G. Subias, V. Padial, M. Carballo, J. E. Collazos-Castro, N. Casañ-Pastor, J Phys Chem C 2012, 116, 5155.

[7] N. K. Guimard, N. Gomez, C. E. Schmidt, Prog Polymer Sci (Oxford) 2007, 32, 876.

[8] J. Moral-Vico, N. M. Carretero, E. Pérez, C. Suñol, M. Lichtenstein, N. Casañ-Pastor, Electrochim. Acta 2013, 111, 250.

[9] A. M. Rajnicek, K. R. Robinson, C. D. McCaig, Dev Biol 1998, 203, 412.

[10] A. M. Rajnicek, L. Foubister, C. D. McCaig, J Cell Sci 2006, 119, 1723.

[11] A. M. Rajnicek, N.A.R. Gow, C. D. McCaig, Exper Physiol 1992, 77, 229.

[12] R. W. Davenport, C. D. McCaig, J Neurobiol 1993, 24, 89.

[13] S. E. Fosdick, K. N. Knust, K. Scida, R. M. Crooks, Angew Chem Int Ed 2013, 52, 10438.

[14] A. M. Cruz, N. Casañ-Pastor, Thin Solid Films 2013, 534, 316.

[15] J. Moral-Vico, S. Sanchez-Redondo, M. P. Lichtenstein, C. Suñol, N. Casañ -Pastor, Acta Biomaterialia 2015, 10, 2177.

[16] M. Canillas, B Moreno, E. Chinarro, A. M. Rajnicek, .J Mat Chem C 2017, 79, 1.

[17] J. E. Collazos-Castro, A. M. Cruz, M. Carballo-Vila, M. Lira-Cantu, L. Abad, A. Perez del Pino, J. Fraxedas, A. San Juan, C. Fonseca, N. Casan-Pastor, Thin Solid Films 2009, 518, 160.

[18] M. P. Lichtenstein, E. Pérez, L. Ballesteros, C. Suñol, N. Casañ-Pastor, Appl Mater Today2017, 6, 29.

[19] K. A. Chang, J. W. Kim, J. Kim, S. Lee, S. Kim, W. H. Suh, H. S. Kim, S. Kwon, S. J. Kim, Y.H. Suh, PLoS ONE 2011, 6, e18738. doi:10.1371/journal.pone.0018738.

[20] M. A. Petit, V. Plinchon, J Electroanal Chem 1998, 444, 247.

[21] J. E. Baur, T. W. Spaine, J Electroanal Chem 1998, 443, 208. 


\section{WILEY-VCH}

[22] K. K. Kasem, S. Jones, Platinum Met Rev 2008, 52, 100.

[23] J. Moral-Vico, PhD Thesis, CSIC, Universidad Autónoma de Barcelona, Spain 2012 , http://www.tdx.cat/handle/10803/402490.

[24] N. T. J. Bailey, Statistical Methods in Biology, Hodder and Stoughton, London, 1981. pp. 38.

[25] T. Smith, J Coll Int Sci 1980, 75, 51.

[26] K. B. Hotary, K. R. Robinson, Dev Brain Res 1991, 59, 65.

[27] a) M. Gabi, A. Larmagnac, P. Schulte, J. Voros, Colloids and Surfaces B: Biointerfaces 2010, 79, 365; b) K. V. Gopal, C. Wu, B. Shrestha, K. C. M. Campbell, E. J. Moore, G. W. Gross, Neurotoxicology and Teratology 2012, 34, 495 c) G. W. Gross, W. Y. Wen, J. W. Lin, J Neurosci Methods 1985, 15, 243; d) K. A. Chang, J. W. Kim, J. Kim, S. Lee, S. Kim, W. H. Suh, H. S. Kim, S. Kwon, S. J. Kim, Y. H. Suh, PLoS ONE 2011, 6, e18738. doi:10.1371/journal.pone.0018738.

[28] G. W. Gross, W. Y. Wen, J. W. Lin, J Neurosci Methods 1985, 15, 243.

[29] B. Gupta, B. Goudeau, A. Kuhn, Angew Chem Int Ed 2017, 56, 14183.

[30] a) E. M. Pérez, P. Lichtenstein, C. Suñol, N. Casañ-Pastor N, Mat Sci Engin C 2015, 55, 218; N. M. Carretero, M.P. Lichtenstein, E. Pérez, S. Sandoval, G. Tobias, C. Suñol, N. Casan-Pastor, Electrochimica Acta 2015, 157, 369.

[31] N. Carretero, PhD Thesis, 2014, CSIC, Universidad Autónoma de Barcelona, Spain. http://www.tdx.cat/handle/10803/283440.

[32] a) C. E. Schmidt, V. R. Shastri, J. P. Vacanti, R. Langer, Proc Natl Acad Sci USA 1997, 94, 8948; b) L. Ouyang, C. L. Shaw, C. Kuo1, A. L. Griffin, D. C. Martin, J Neural Eng 2014, 11, doi:10.1088/1741-2560/11/2/026005; c) B. C. Thompson, R. T. Richardson, S. E.

Moulton, A. J. Evans, S. O'Leary, G. M. Clark, G. G. Wallace, J Controlled Release, 2010, 141, 161;d) M. Asplund, C. Bohler, T. Stiglitz, Frontiers in Neuroengin 2014, 7,doi: 10.3389/fneng.2014.00009. 


\section{WILEY-VCH}
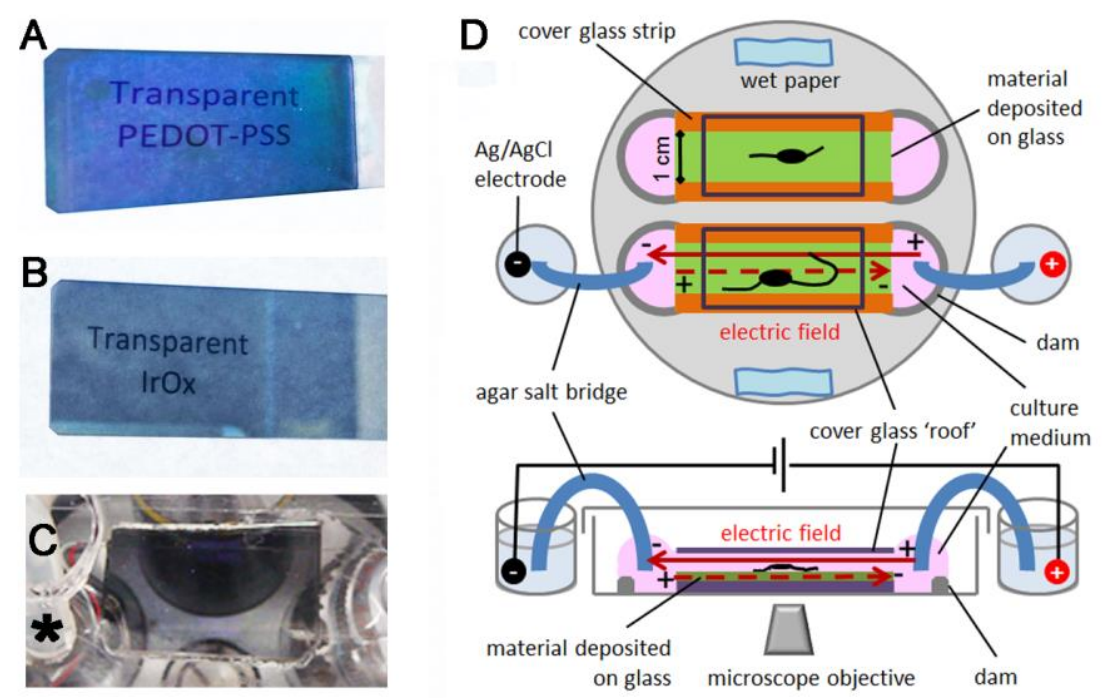

Figure 1. Experimental scheme. A and B) Transparency of materials (blue) electrodeposited onto glass. C) IrOx material during an electric field experiment. The end of an agar bridge is visible (asterisk) and the microscope objective turret can be seen through the material. D) The electric field set up. Control (no electric field) and electric field conditions were run in parallel. Materials were not 'wired' directly to the power supply. Arrows indicate the imposed external electric field (solid red arrow) in the culture medium and the dipole (dotted red arrow) of opposite polarity induced within the materials on which the neurons grew. For some experiments the cells grew directly on the plastic and the materials were omitted. ${ }^{[10,16]}$ 

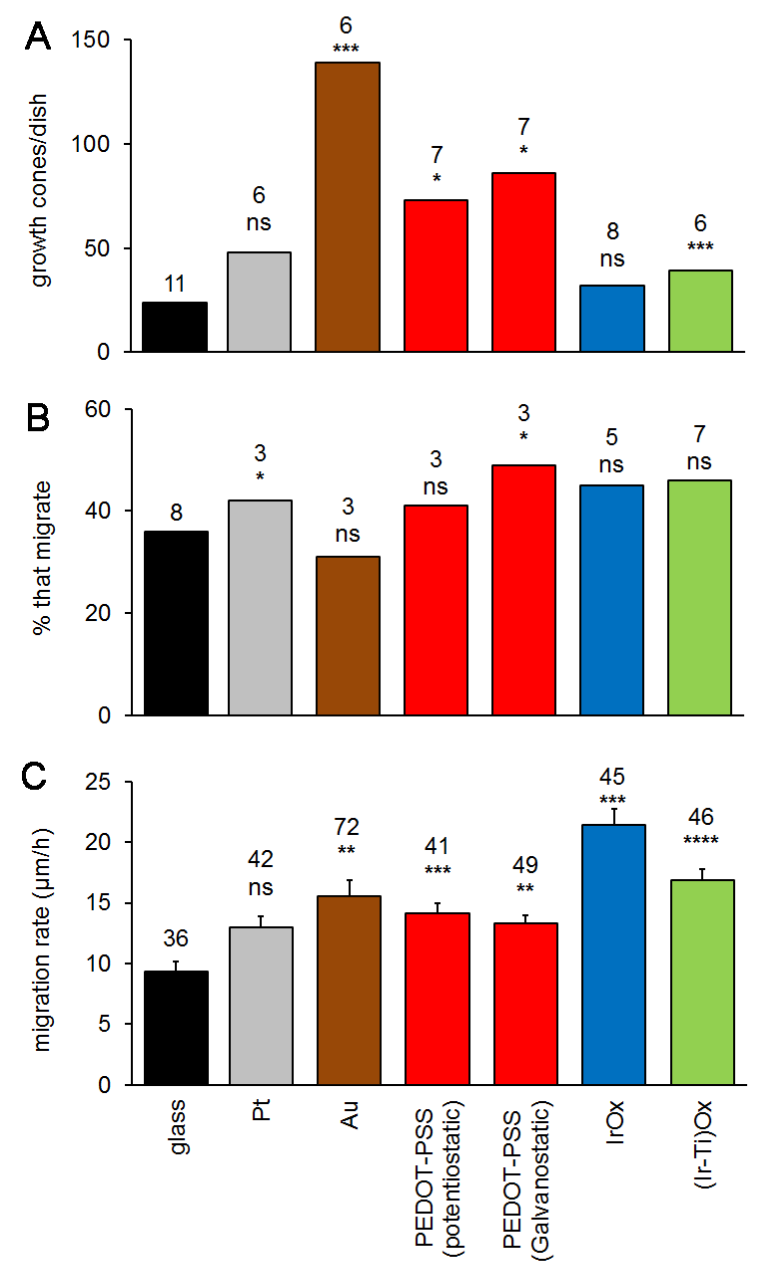

Figure 2. Neuron growth during 3 hours without electrical stimulation. A) The number of growth cones per dish. B) The percentage that advanced continuously. C) The rate of growth cone advance (mean \pm SEM). The numbers above each bar represent $(A)$ the total number of dishes, (B) the total number of experiments and (C) the number of growth cones measured. Statistics compare to glass: $* p \leq 0.05, * * p \leq 0.005, * * * p \leq 0.001, * * * * p \leq 0.0001, \mathrm{~ns}=$ no significant difference. D test (A and B) and unpaired 2-tailed Student's t test (C). 
WILEY-VCH

A

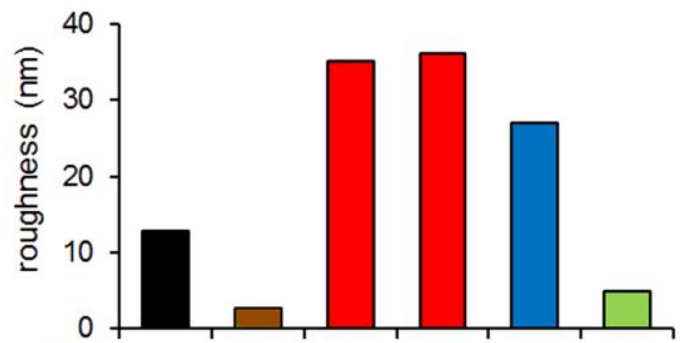

B
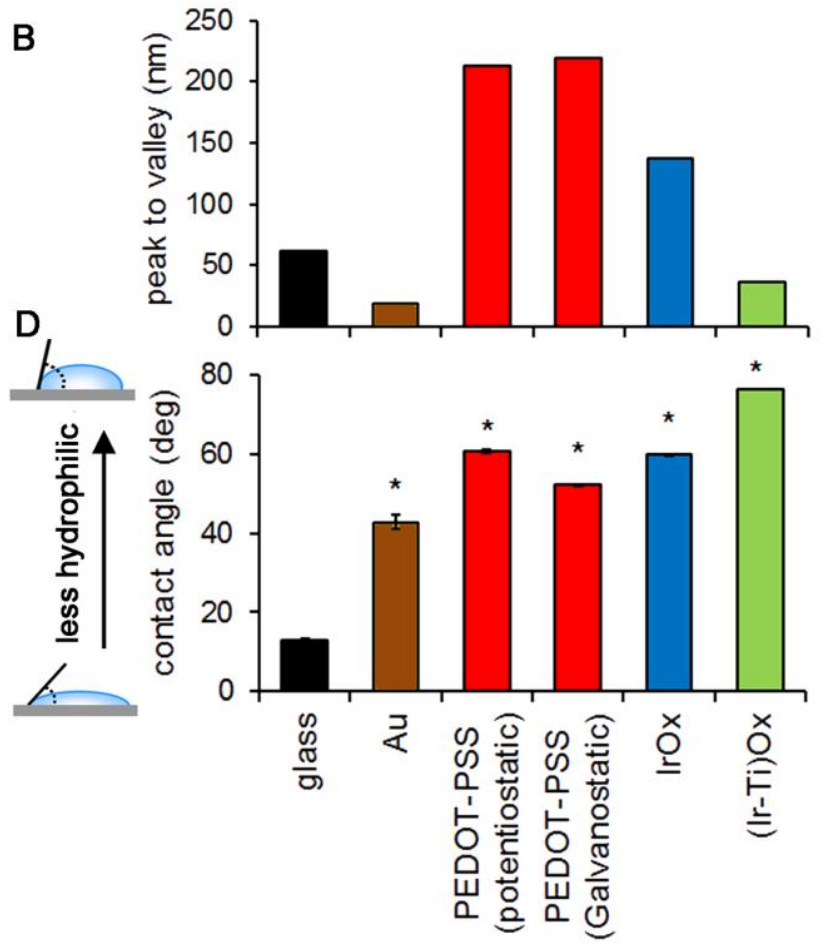

\section{C $\quad 50 \mathrm{~nm}$}

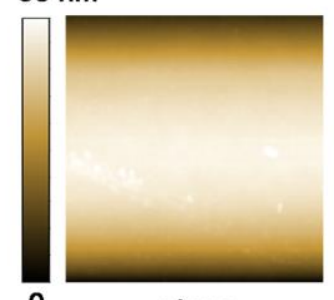

glass $200 \mathrm{~nm}$

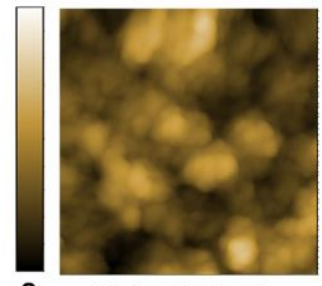

PEDOT-PSS

potentiostatic

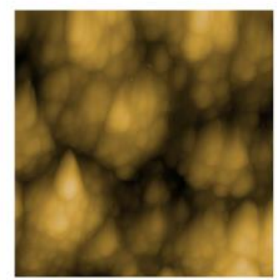

IrOx

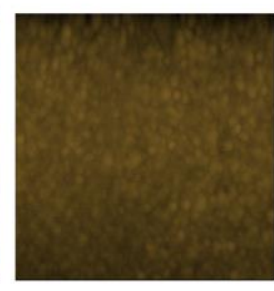

Au

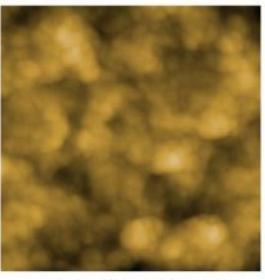

PEDOT-PSS

Galvanostatic

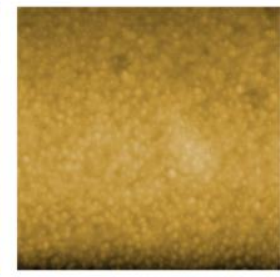

(Ir-Ti)Ox

Figure 3. Surface characteristics. A) Roughness; the average distance between topographic features. B) The peak to valley distance; the height the features. C) Atomic force microscopy images of a $1 \mu \mathrm{m}^{2}$ area. Pixel intensity indicates surface feature height where the 0 to $50 \mathrm{~nm}$ scale bar applies to glass, $\mathrm{Au}$ and (Ir-Ti)Ox and the 0 to $200 \mathrm{~nm}$ scale bar applies to IrOx and both PEDOT-PSS materials. D) Surface hydrophilicity from contact angle measurements ( $\mathrm{n}=$ 20 ; mean $\pm S D$ ) of water droplets. ${ }^{*} p<0.001$ compared to glass. Errors are too small to be visible on most bars. 


\section{WILEY-VCH}
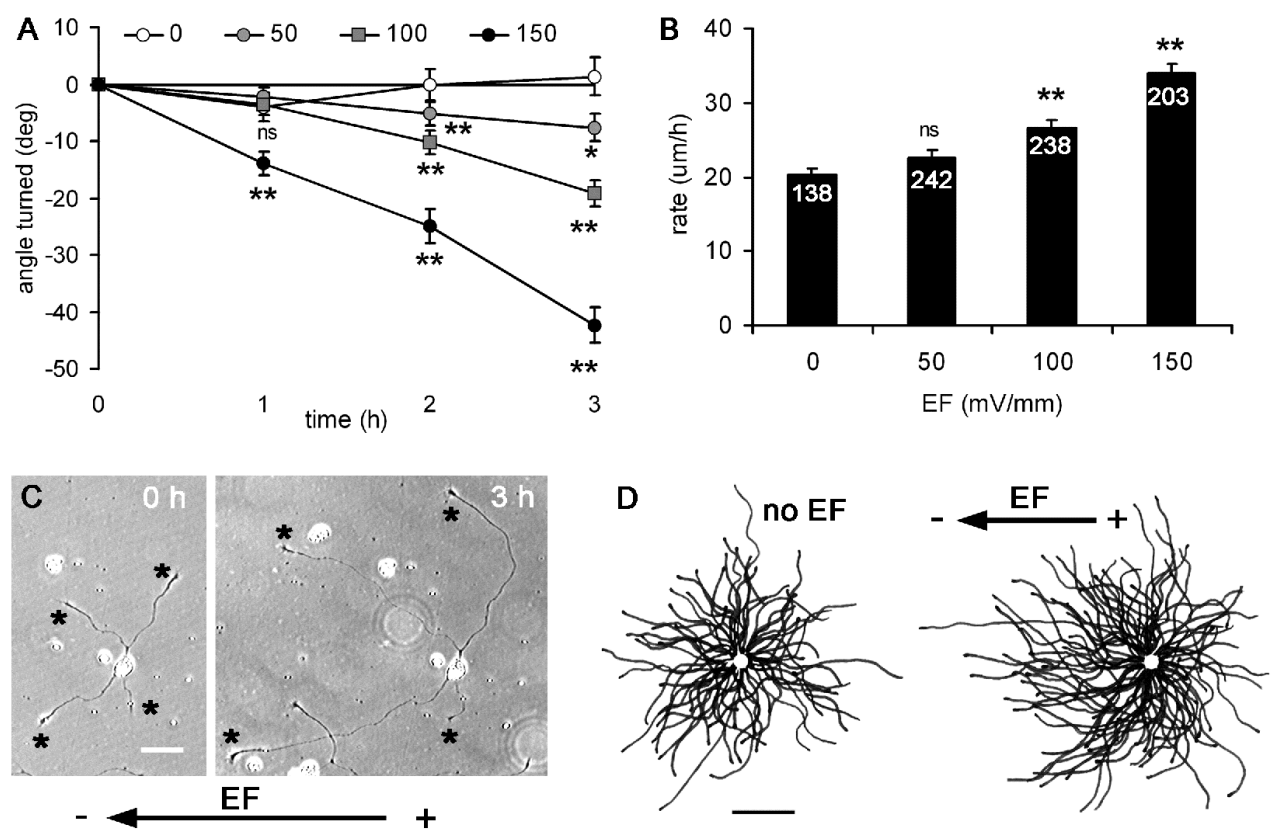

Figure 4. Growth on a plastic (insulating) substratum. A) Angle of deflection with no electric field (EF $0 \mathrm{mV} \mathrm{mm}^{-1}$ ) or when stimulated using $50 \mathrm{mV} \mathrm{mm}^{-1}, 100 \mathrm{mV} \mathrm{mm}^{-1}$ or $150 \mathrm{mV} \mathrm{mm}^{-1}$. Negative values indicate cathodal deflection. B) Rate of growth cone advance. Numbers indicate the number of growth cones measured. C) A neuron with 4 growth cones (asterisks) at the start and after $3 \mathrm{~h}$ at $150 \mathrm{mV} \mathrm{mm}^{-1}$. Scale $50 \mu \mathrm{m}$. D) Composite drawings of cells after $3 \mathrm{~h}$ without an electric field or at $50 \mathrm{mV} \mathrm{mm}^{-1}$. Cell bodies of many neurons were superimposed and their neurites were traced. Scale $100 \mu \mathrm{m}$. Student's 2 tailed $t$-test relative to no electric field: $* \mathrm{p}<0.05 ; * * \mathrm{p}<0.005$. 


\section{WILEY-VCH}
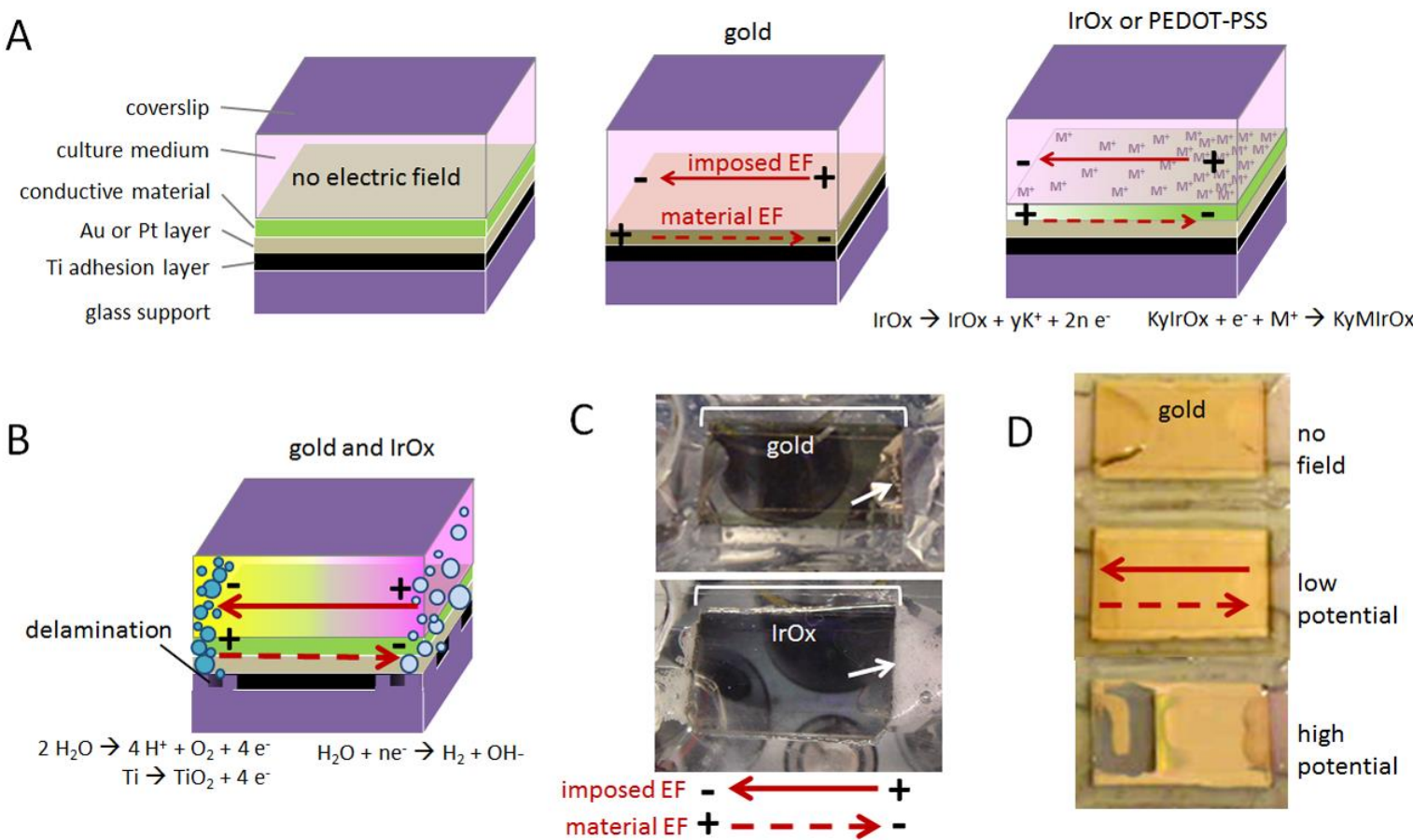

Figure 5. Electrochemical processes in conductive materials. The solid arrows represent the external electric field imposed in the culture medium and the dotted arrows represent the electric dipole induced indirectly within the conductive substrate material. The likely electrochemical processes at the polar edges of the materials are shown. A) At low potentials $\left(50 \mathrm{mV} \mathrm{mm} \mathrm{m}^{-1}\right)$ a dipole is created in IrOx or PEDOT-PSS, resulting in a cation $\left(\mathrm{M}^{+}\right)$gradient within the material. B) At high $\left(\geq 100 \mathrm{mV} \mathrm{mm}^{-1}\right)$ potentials the underlying titanium adhesion layer oxidizes and breaks down, initiating hydrolysis at the material margins. C) $\mathrm{H}_{2}$ and $\mathrm{O}_{2}$ bubbles (white arrows) near materials (white brackets) stimulated at $100 \mathrm{mV} \mathrm{mm}^{-1}$ for $3 \mathrm{~h}$. D) The gold layer remained intact after $3 \mathrm{~h}$ at $50 \mathrm{mV} \mathrm{mm}^{-1}$ (low potential) but it delaminated at $100 \mathrm{mV} \mathrm{mm}^{-1}$ (high potential) as the titanium adhesion layer broke down, causing gold delamination, hydrolytic bubbles, and $\mathrm{pH}$ changes (pink indicates $\mathrm{pH}$ increase at induced cathode; yellow indicates $\mathrm{pH}$ decrease at induced anode). 

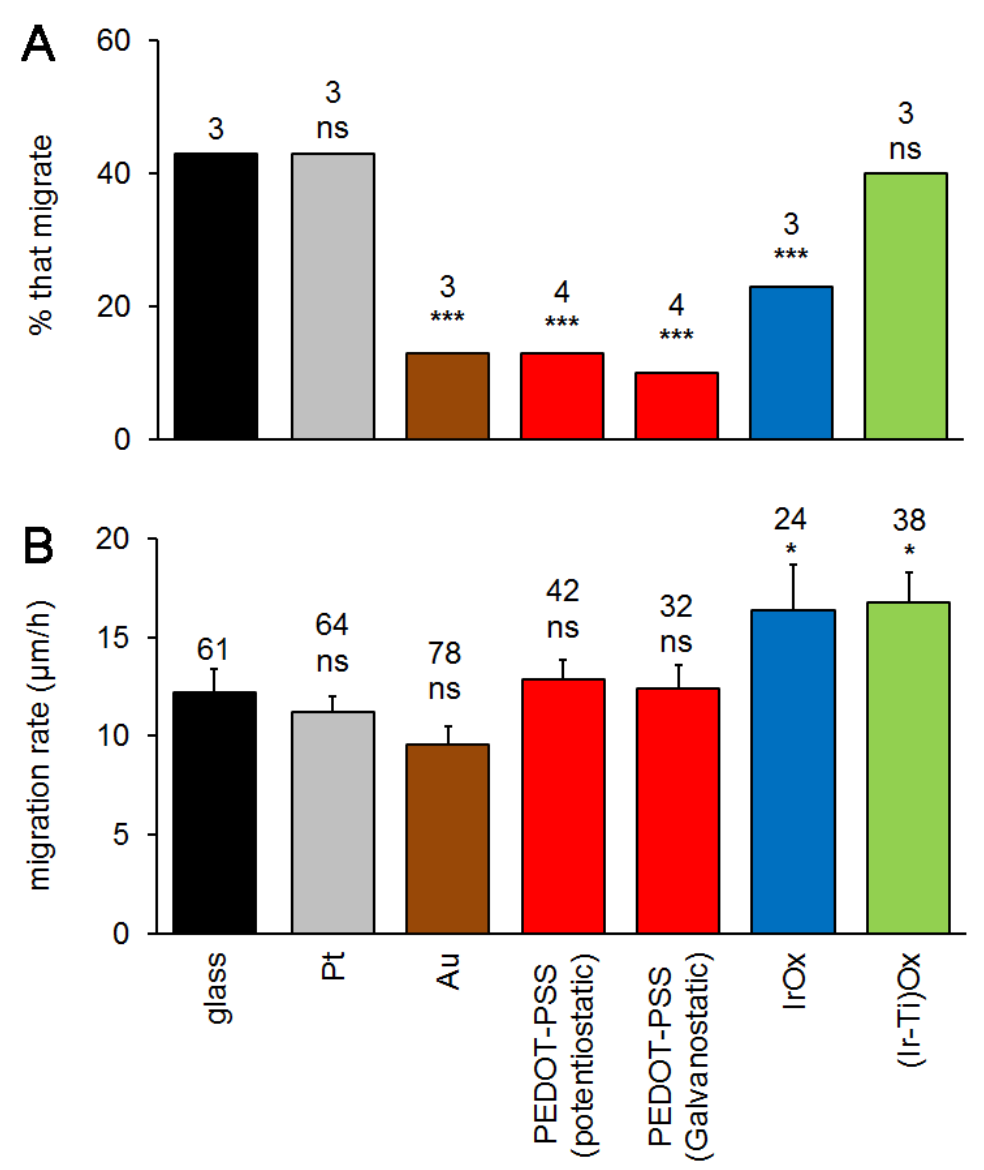

Figure 6. Neuron growth during exposure to an external electric field of $50 \mathrm{mV} \mathrm{mm}^{-1}$. A)

Frequency of growth cones that advance continuously during the experiment. The number of dishes is shown. B) Mean rate of growth cone advance $( \pm$ SEM) (Student's 2 tailed $t)$.

Statistics compared to glass: $* p \leq 0.05, * * p \leq 0.005, * * * p \leq 0.001$, ns $=$ not significant. 

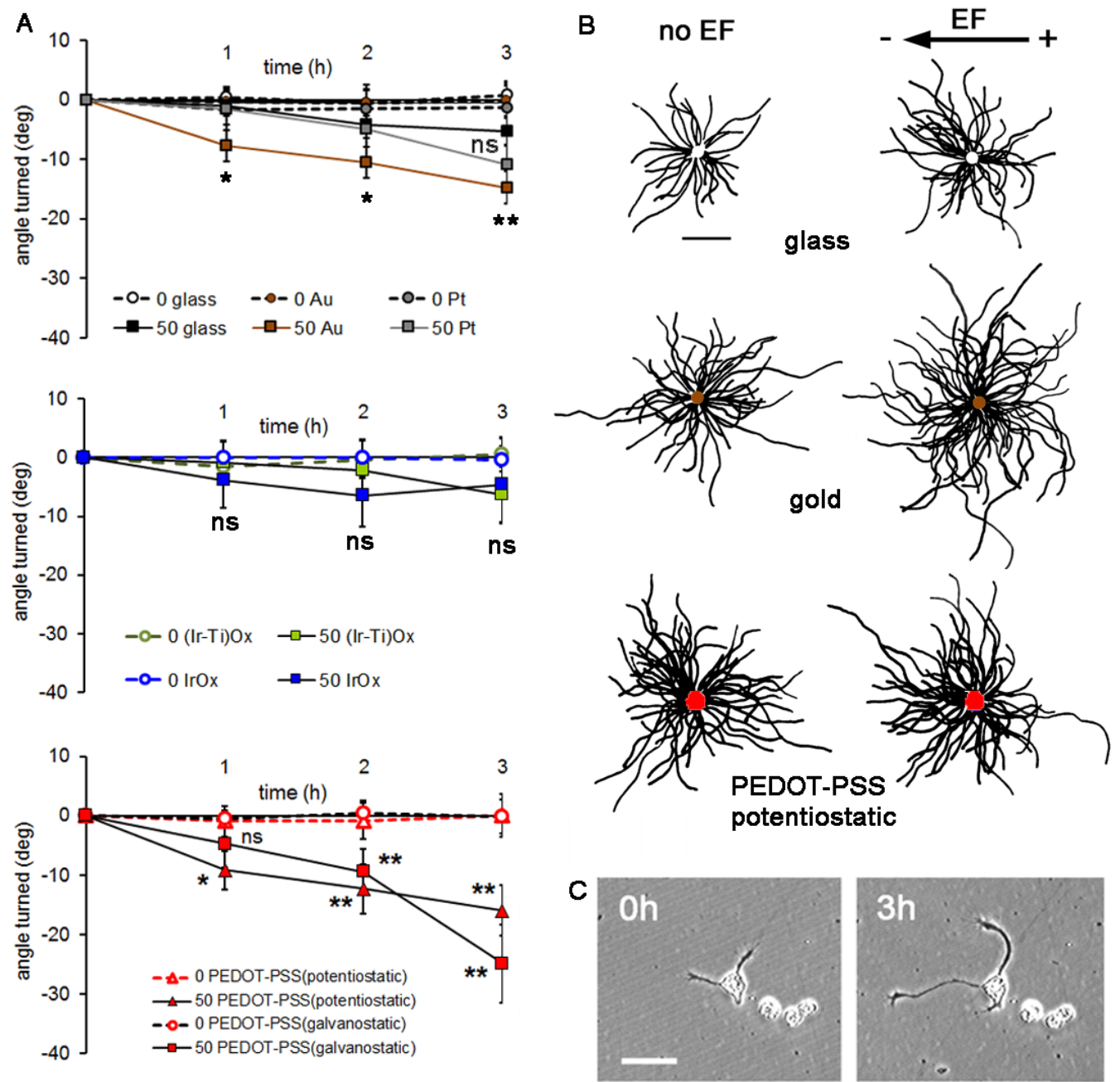

Figure 7. Neuron growth during $50 \mathrm{mV} \mathrm{mm}^{-1}$ external electric field (EF) stimulation. A) The angle of growth cone migration. Negative values indicate migration toward the external cathode; zero indicates randomly directed migration. Statistics compare to the same substrates but without an EF (Student's 2-tailed $t) .{ }^{*} p \leq 0.05,{ }^{*} p \leq 0.005, \mathrm{~ns}=$ no significant difference. $\mathrm{N}$ numbers are as in Figure 6. B) Composite drawings made by superimposing the cell bodies and tracing each neurite. Scale $100 \mu \mathrm{m}$. The electric field vector represents the external field imposed within the culture medium. C) A neuron growing on PEDOT-PSS(galvanostatic). Scale $50 \mu \mathrm{m}$. 


\section{WILEY-VCH}

Table 1. Qualitative summary of neuron growth on materials compared to glass

\begin{tabular}{|c|c|c|c|c|c|}
\hline Material & Sproutinga) & Electric Fieldb) & \multicolumn{3}{|c|}{ Dynamic Behavior } \\
\hline & $\begin{array}{c}\text { Growth } \\
\text { cones dish }^{-1}\end{array}$ & & $\begin{array}{l}\text { Sustained } \\
\text { migrationc) }\end{array}$ & $\begin{array}{l}\text { Migration } \\
\text { speedc) }\end{array}$ & $\begin{array}{l}\text { Directed } \\
\text { to } \\
\text { cathode }^{\text {d) }}\end{array}$ \\
\hline \multirow[t]{2}{*}{ platinum } & $\leftrightarrow$ & no & $\uparrow$ & $\leftrightarrow$ & \\
\hline & & yes & $\leftrightarrow$ & $\leftrightarrow$ & $\leftrightarrow$ \\
\hline \multirow[t]{2}{*}{ gold } & $\uparrow$ & no & $\leftrightarrow$ & $\uparrow$ & \\
\hline & & yes & $\downarrow$ & $\leftrightarrow$ & $\uparrow$ \\
\hline \multirow{2}{*}{$\begin{array}{l}\text { PEDOT-PSS } \\
\text { (potentiostatic) }\end{array}$} & $\uparrow$ & no & $\leftrightarrow$ & $\uparrow$ & \\
\hline & & yes & $\downarrow$ & $\leftrightarrow$ & $\uparrow$ \\
\hline \multirow{2}{*}{$\begin{array}{l}\text { PEDOT-PSS } \\
\text { (galvanostatic) }\end{array}$} & $\uparrow$ & no & $\uparrow$ & $\uparrow$ & \\
\hline & & yes & $\downarrow$ & $\leftrightarrow$ & $\uparrow$ \\
\hline \multirow[t]{2}{*}{$\mathrm{IrOx}$} & $\leftrightarrow$ & no & $\leftrightarrow$ & $\uparrow$ & \\
\hline & & yes & $\downarrow$ & $\uparrow$ & $\leftrightarrow$ \\
\hline \multirow[t]{2}{*}{$(\mathrm{Ir}-\mathrm{Ti}) \mathrm{Ox}$} & $\uparrow$ & no & $\leftrightarrow$ & $\uparrow$ & \\
\hline & & yes & $\leftrightarrow$ & $\uparrow$ & $\leftrightarrow$ \\
\hline
\end{tabular}

Key: $\uparrow$ significantly better; $\downarrow$ significantly worse; $\leftrightarrow$ no change. ${ }^{\text {a) }}$ Sprouting was quantified only for no electric field conditions and compared to glass. ${ }^{\text {b) }}$ External imposed field of $50 \mathrm{mV} \mathrm{mm}^{-1}$. ${ }^{\mathrm{c})}$ Compared to responses on glass under the same electric field condition. ${ }^{\text {d) }}$ Compared to glass during electric field stimulation. 


\section{WILEY-VCH}

Title Controlling Nerve Growth with an Electric Field Induced Indirectly in Transparent Conductive Substrate Materials

Thin, transparent films of conductive materials are shown to support and control nerve growth when an electric dipole is imposed in them wirelessly. Neurons growing on the materials react to the dipole imposed in them indirectly by electrodes in the culture medium. This observation is important for refining electrostimulation therapies that exploit wireless stimulation of implanted conductive material arrays, even where transparency is required.

Keywords conducting polymers, bipolar electrochemistry, neurostimulation, transparent electrodes, oxides
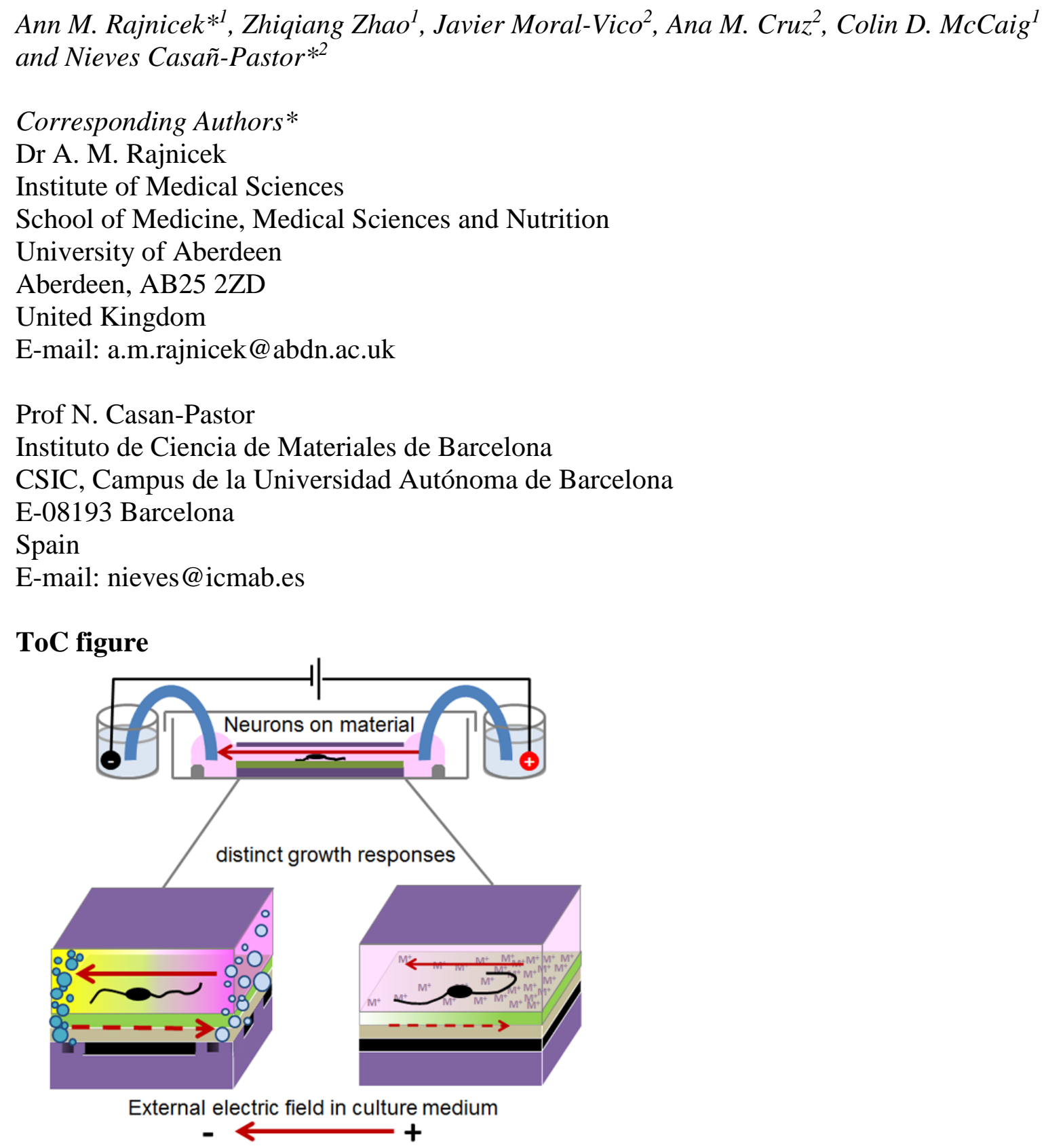

Dipole induced indirectly (wirelessly) in the substrate material

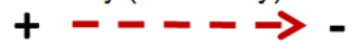




\section{WILEY-VCH}

Copyright WILEY-VCH Verlag GmbH \& Co. KGaA, 69469 Weinheim, Germany, 2016.

\section{Supporting Information}

\section{Controlling Nerve Growth with an Electric Field Induced Indirectly in Transparent Conductive Substrate Materials}

Ann M. Rajnicek*1, Zhiqiang Zhao ${ }^{1}$, Javier Moral-Vico ${ }^{2}$, Ana M. Cruz ${ }^{2}$, Colin D. McCaig ${ }^{1}$ and Nieves Casañ-Pastor $*^{2}$

Corresponding Author $(s)^{*}$

Dr A. M. Rajnicek

Institute of Medical Sciences

University of Aberdeen

Aberdeen, AB25 2ZD

United Kingdom

E-mail: a.m.rajnicek@abdn.ac.uk

Prof N. Casan-Pastor

Instituto de Ciencia de Materiales de Barcelona

CSIC, Campus de la Universidad Autónoma de Barcelona

E-08193 Barcelona

Spain

E-mail: nieves@icmab.es

\section{Supporting Information}

Synthesis of transparent conductive materials

Materials, prepared as transparent thin films on glass or quartz are summarised in Table S1. Soda lime glass slides $(25 \mathrm{~mm}$ x $60 \mathrm{~mm})$ coated with a $300 \mathrm{~nm}$ layer of indium tin oxide (ITO) (Solems YSUB/ITOSOL) were used for deposition of $\mathrm{TiO}_{2}$. For deposition of $\mathrm{IrO}_{\mathrm{x}}$ and polymers soda lime glass slides (AFORA KN26X76TB; 24mm x 70mm) were coated by thermal evaporation with a $5 \mathrm{~nm}$ thick adhesion layer of $\mathrm{Ti}$ followed by either $\mathrm{Au}$ $(15 \mathrm{~nm})$ or $\mathrm{Pt}(12 \mathrm{~nm})$.

Glass, $\mathrm{TiO}_{2}$ and (Ir-Ti)Ox materials classify as insulators. Au and Pt materials are metallic, with only electronic conduction behaviour. IrOx, polypyrrole-PPY based and PEDOT based materials are conducting, with mixed ionic-electronic conductivity and intercalation properties. PPY and PEDOT may have various counterions. A summary of 


\section{WILEY-VCH}

previously tested charge storage capacities (injection capacity) in DC electric fields is included in Table S1. Impedance values are discussed in Lichtensein et al., 2017. ${ }^{[7]}$ References in the main paper refer to the electrostimulation applications tested in the case of metals and mixed ionic-electronic conductors. The larger charge capacity in mixed ionicelectronic conductors offers a longer and safer stimulation process.

IrOx thin films were prepared using a novel dynamic electrodeposition procedure modified to optimise adhesion. ${ }^{[1]}$ Briefly, $50 \mathrm{ml}$ of solution ( $\mathrm{pH}$ 10) was prepared by dissolving sequentially, $2 \cdot 10^{-4}$ moles of $\mathrm{IrCl}_{3} \cdot \mathrm{H}_{2} \mathrm{O}$ (Aldrich $99.9 \%$ ), $1 \cdot 10^{-3}$ moles of oxalic acid, $\mathrm{H}_{2} \mathrm{C}_{2} \mathrm{O}_{4} \cdot 2 \mathrm{H}_{2} \mathrm{O}$ (Aldrich 99\%) and $5 \cdot 10^{-3}$ moles of $\mathrm{K}_{2} \mathrm{CO}_{3}$ (Aldrich, 99\%) in water. The solution was kept at $37^{\circ} \mathrm{C}$ for 4 days and then at $4^{\circ} \mathrm{C}$ until use. Aging changes the colour of the solution, indicating a change in the Ir ion coordination sphere. Electrodeposition used a VMP potentiostat (Bio-logic). A three-electrode cell system consisted of a Pt counter electrode and a working electrode with the same dimensions and a Pt quasi-reference electrode with a potential equal to that versus $\mathrm{Ag} / \mathrm{AgCl}$. This pseudo-reference $\mathrm{Pt}$ is stable versus $\mathrm{Ag} / \mathrm{AgCl}$ during $\mathrm{CV}$, possibly due to the formation of an oxide on the surface. ${ }^{[2]}$. Positive and negative electrodes were separated by $1 \mathrm{~cm}$ using Teflon.

$\mathrm{TiO}_{2}$ coatings (anatase) on ITO coated glass were obtained by spin coating ethanol solutions of $0.7 \mathrm{M}$ titanium isopropoxide (Ti(OiPr) 4 99.9\%, Aldrich) and $1.4 \mathrm{M}$ acetylacetone (99\%, Aldrich) aged for 1 day and then $0.2 \mu \mathrm{m}$ filtered. ${ }^{[3]}$ Spin coating was done in three layers using a spin processor (Laurell Technologies Corporation) at $3000 \mathrm{rpm}$. Films were annealed for $2 \mathrm{~h}$ at $350^{\circ} \mathrm{C}$ after each layer.

Ir-Ti mixed oxides were prepared on quartz slides (VWR International) following thermal evaporation with a $5 \mathrm{~nm}$ Ti adhesion layer followed by $12 \mathrm{~nm}$ of Pt. (Ir-Ti)Ox films were prepared by spin coating ethanol solutions of titanium (IV) and iridium (III) salts. ${ }^{[4]}$ The Ir-Ti solution was prepared by mixing equal volumes of Ti and Ir solutions. The $0.21 \mathrm{M} \mathrm{Ti}$ solution (50 ml final volume) made as Titanium isopropoxide (Ti(OiPr) $499.99 \%$, Aldrich 


\section{WILEY-VCH}

$0.011 \mathrm{M})$ dissolved in ethanol in the presence of acetylacetone $(99+\%$, Aldrich $0.024 \mathrm{M})$ and aged for one day. $0.024 \mathrm{M}$ iridium (III) chloride solutions $\left(1.2 \cdot 10^{-3} \mathrm{M}\right.$ of $\mathrm{IrCl}_{3} \cdot \mathrm{xH}_{2} \mathrm{O} 99.9 \%$, Aldrich) were prepared at Ir:Ti 1:10 and in $0.048 \mathrm{M}$ concentration to achieve final ratios Ir:Ti 2:10. Both contained acetic acid $\left(\mathrm{CH}_{3} \mathrm{COOH} 99 \%\right.$ Aldrich $)$ in six fold excess with respect to Ir. The solutions were mixed and filtered $(0.2 \mu \mathrm{m})$ prior to spin coating at $3000 \mathrm{rpm}$ using a spin processor (Laurell Technologies Corporation). Monolayers with a Ir:Ti ratio 1:10 were annealed at $600^{\circ} \mathrm{C}$ during $4 \mathrm{~h}$ or $6 \mathrm{~h}$ and at $650^{\circ} \mathrm{C}$ for $4 \mathrm{~h}$ or $6 \mathrm{~h}$. Three layer coatings with the Ir:Ti ratio 1:10 and 2:10 were prepared and annealed at $600^{\circ} \mathrm{C}$ for $6 \mathrm{~h}^{[4]}$

PEDOT-based materials poly(3,4-ethylenedioxythiophene) (PEDOT) were prepared from the monomer 3,4-(ethylenedioxy)thiophene (EDOT) (Sigma-Aldrich, 97\%) stored at $4^{\circ} \mathrm{C}$ until use. ${ }^{[5]}$ Before use, the $0.01 \mathrm{M}$ EDOT solution mixed with the different counterions was deoxygenated under argon for 30 min. Polymerization of PEDOT was performed using a potentiostat/galvanostat (Bio-logic Science Instruments) in a three-electrode configuration; with a Pt sheet (Good Fellow 99.9\%) as the counter electrode and a Pt wire as a quasireference electrode. The working electrode was a $5 \mathrm{~nm} \mathrm{Ti} / 12 \mathrm{~nm}$ Pt film deposited on a sodalime glass slide. For PEDOT-PSS synthesis the electropolymerization solution contained 0.1 M Poly(3,4-sodium styrene sulfonate) (PSS). PEDOT-PSS films were synthesized potentiostatically at $0.9 \mathrm{~V}$ versus reference (PEDOT-PSS ${ }^{\mathrm{a}}$ ) and galvanostatically with a current of $1.25 \mathrm{~mA}$ (PEDOT-PSS ${ }^{\mathrm{b}}$ ). The reaction was stopped when a charge of $900 \mathrm{mC}$ was reached over an area of $10 \mathrm{~cm}^{2}$. For PEDOT-PSS ${ }^{\mathrm{c}}$ the reaction was stopped at $4000 \mathrm{mC}$. For PEDOT-glutamine synthesis films were synthesized as above but with $0.1 \mathrm{M}$ phosphate buffer with 0.1 M L-glutamine (Sigma) replacing PSS in the electropolymerization solution. The working electrode for polymerization was a $5 \mathrm{~nm} \mathrm{Ti} / 12 \mathrm{~nm}$ Pt film deposited on a soda lime glass. PEDOT-glutamine films were synthesized dynamically from open circuit potential (OCP) until $0.9 \mathrm{~V}$ versus reference at $5 \mathrm{~m} \mathrm{~V} / \mathrm{s}$, reaching $1000 \mathrm{mC} .^{[5,6]}$ 


\section{WILEY-VCH}

Polypyrrole (PPY)-based coatings were prepared from pyrrole (Sigma-Aldrich, 98\%) vacuum-distilled until colourless and stored at $-10{ }^{\circ} \mathrm{C}$ then deoxygenated under argon for 30 min prior to polymerization. The potentiostat/galvanostat three electrode configuration for electropolymerization was as described for PEDOT materials. PPY-dodecylbenzene sulfonate (DBS) or PPY-Poly(3,4-sodium styrene sulfonate) (PPY-PSS) synthesis was performed from 0.1 M sodium dodecylbenzene sulfonate (or Poly(3,4-sodium styrene sulfonate)) and $0.1 \mathrm{M}$ pyrrole. The working electrode was a $5 \mathrm{~nm} \mathrm{Ti} / 15 \mathrm{~nm}$ Au film deposited on soda-lime glass (for DBS) or Pt (for PSS. PPY-DBS). Films were synthesized by a dynamic electrodeposition method that cycled the potential from the open circuit voltage to $0.6 \mathrm{~V}$ vs reference at a rate of $5 \mathrm{mV} / \mathrm{s}$, while PPY-PSS films were deposited potentiostatically at $0.6 \mathrm{~V}$ vs Pt reference. PPY-perchlorate was prepared in the same way from solutions of 0.1 M pyrrole and 0.1 M sodium perchlorate (Riedel-de-Haën, pure) using acetonitrile (Aldrich, $99 \%$ ) as a solvent instead of water. The substrate electrode was a $5 \mathrm{~nm} \mathrm{Ti} / 12 \mathrm{~nm}$ Pt film on soda lime glass. The initial sweep was from open circuit to $0.75 \mathrm{~V}$ versus reference. ${ }^{[5,6]}$ Before use slides were rinsed with Milli Q water and secured material side $\mathrm{u}$ ) in the electric field chamber (Figure 1). Neurons were plated onto prepared materials without further surface treatment. 


\section{WILEY-VCH}

Table S1 Summary of material synthesis and chare storage capacity

\begin{tabular}{|c|c|c|c|c|}
\hline Material & Substrate & Preparationa) & $\begin{array}{l}\text { Material } \\
\text { Thickness (nm) }\end{array}$ & $\begin{array}{l}\text { Charge Storage } \\
\left.\text { Capacity }{ }^{b}\right)\end{array}$ \\
\hline $\begin{array}{l}\text { Soda lime } \\
\text { glass }\end{array}$ & & none & & \\
\hline ITO & glass & As purchased (Solemns) & 300 & - \\
\hline $\mathrm{Pt}$ & $\begin{array}{l}\text { Soda lime } \\
\text { glass }\end{array}$ & $\begin{array}{l}\text { Thermal evaporation of } 5 \mathrm{~nm} \mathrm{Ti} \text { then } \\
\text { thermal evaporation of } 12 \mathrm{~nm} \mathrm{Pt}\end{array}$ & $\begin{array}{l}12 \text { (transparency } \\
\text { limit) }\end{array}$ & $\approx \mu \mathrm{C} / \mathrm{cm}^{2}[1,7]$ \\
\hline $\mathrm{Au}$ & $\begin{array}{l}\text { Soda lime } \\
\text { glass }\end{array}$ & $\begin{array}{l}\text { Thermal evaporation of } 5 \mathrm{~nm} \text { Ti then } \\
\text { thermal evaporation of } 15 \mathrm{~nm} \mathrm{Au}\end{array}$ & $\begin{array}{l}15 \text { (transparency } \\
\text { limit) }\end{array}$ & $\approx \mu \mathrm{C} / \mathrm{cm}^{2}[1]$ \\
\hline PPY-DBS & $\begin{array}{l}\text { Au-coated } \\
\text { glass }\end{array}$ & $\begin{array}{l}\text { Dynamic potential electrodeposition } 0 \\
\text { to } 0.6 \mathrm{~V}\end{array}$ & 570 & $5-10 \mathrm{mC} / \mathrm{cm}^{2}[5,6]$ \\
\hline $\begin{array}{l}\text { PPY- } \\
\text { perchlorate }\end{array}$ & $\begin{array}{l}\text { Pt- coated } \\
\text { glass }\end{array}$ & Dynamic potential electrodeposition & 250 & $5-10 \mathrm{mC} / \mathrm{cm}^{2}[5,6]$ \\
\hline PPY-PSS & $\begin{array}{l}\text { Pt-coated } \\
\text { glass }\end{array}$ & $\begin{array}{l}\text { Dynamic potential electrodeposition up } \\
\text { to } 0.6 \mathrm{~V}, 1200 \mathrm{mC} \text { total charge }\end{array}$ & 290 & $5-10 \mathrm{mC} / \mathrm{cm}^{2}[5,6]$ \\
\hline $\begin{array}{l}\text { PEDOT- } \\
\text { PSSa }\end{array}$ & $\begin{array}{l}\text { Pt-coated } \\
\text { glass }\end{array}$ & $\begin{array}{l}0.6 \mathrm{~V} \text { potentiostatic, } 900 \mathrm{mC} \text { total } \\
\text { charge }\end{array}$ & 350 & $7 \mathrm{mC} / \mathrm{cm}^{2}[5,6,7]$ \\
\hline $\begin{array}{l}\text { PEDOT- } \\
\text { PSS }\end{array}$ & $\begin{array}{l}\text { Pt-coated } \\
\text { glass }\end{array}$ & $\begin{array}{l}1.25 \mathrm{~mA} \text { galvanostatic control, } 900 \mathrm{mC} \\
\text { total charge }\end{array}$ & 335 & $\begin{array}{l}5-7 \mathrm{mC} / \mathrm{cm}^{2} \\
{[5,6,7]}\end{array}$ \\
\hline $\begin{array}{l}\text { PEDOT- } \\
\text { PSSc }\end{array}$ & $\begin{array}{l}\text { Pt-coated } \\
\text { glass }\end{array}$ & $\begin{array}{l}0.6 \mathrm{~V} \text { potentiostatic, } 4000 \mathrm{mC} \text { total } \\
\text { charge }\end{array}$ & 1550 & $5-7 \mathrm{mC} / \mathrm{cm}^{2}[5,6,7]$ \\
\hline $\begin{array}{l}\text { PEDOT- } \\
\text { glutamine }\end{array}$ & $\begin{array}{l}\text { PT-coated } \\
\text { glass }\end{array}$ & $\begin{array}{l}30 \text { cycles, dynamic deposition, } 1000 \\
\mathrm{mC}\end{array}$ & 90 & $10 \mathrm{mC} / \mathrm{cm}^{2}[5,6,7]$ \\
\hline $\begin{array}{l}\mathrm{TiO}_{2} \\
\text { (anatase) }\end{array}$ & $\begin{array}{l}\text { ITO-coated } \\
\text { glass }\end{array}$ & $\begin{array}{l}\text { Spin coating of propoxide precursor } \\
\text { solutions then heating at } 350^{\circ} \mathrm{C}, 2 \mathrm{~h}, 3 \\
\text { layers }\end{array}$ & 90 & - \\
\hline IrOx & $\begin{array}{l}\text { Pt-coated } \\
\text { glass }\end{array}$ & $\begin{array}{l}\text { Dynamic potential electrodeposition, } \\
50 \text { cycles, } 0 \text { to } 0.55 \mathrm{~V}, 10 \mathrm{mV} / \mathrm{s} 50 \\
\text { cycles, } 0.55 \mathrm{~V}, 10 \mathrm{mV} / \mathrm{s}\end{array}$ & 170 & $20 \mathrm{mC} / \mathrm{cm}^{2}[1,7]$ \\
\hline$(\mathrm{Ir}-\mathrm{Ti}) \mathrm{Ox} \mathrm{x}^{\mathrm{d}}$ & $\begin{array}{l}\text { Pt-coated } \\
\text { quartz }\end{array}$ & $\begin{array}{l}\text { Spin coating of } \mathrm{Ti}(\mathrm{IV}) \text { propoxide and Ir } \\
\text { (III) chloride precursor solutions then } \\
\text { heating at } 600^{\circ} \mathrm{C} 6 \mathrm{~h}, 1 \text { layer (Ti:Ir }= \\
10: 1)\end{array}$ & 60 & - \\
\hline$(\mathrm{Ir}-\mathrm{Ti}) \mathrm{Ox}$ & $\begin{array}{l}\text { Pt-coated } \\
\text { quartz }\end{array}$ & $\begin{array}{l}\text { Spin-coating of propoxide precursor } \\
\text { solutions then heating at } 600^{\circ} \mathrm{C}, 6 \mathrm{~h}, 1 \\
\text { layer (Ti:Ir }=10: 2)\end{array}$ & 60 & - \\
\hline$(\mathrm{Ir}-\mathrm{Ti}) \mathrm{Ox}$ & $\begin{array}{l}\text { Pt-coated } \\
\text { quartz }\end{array}$ & $\begin{array}{l}\text { Spin-coating of propoxide precursor } \\
\text { solutions then heating at } 600^{\circ} \mathrm{C}, 6 \mathrm{~h}, 3 \\
\text { layers (Ti:Ir }=10: 2)\end{array}$ & 180 & - \\
\hline$(\mathrm{Ir}-\mathrm{Ti}) \mathrm{Ox} \mathrm{g}$ & $\begin{array}{l}\text { Pt-coated } \\
\text { quartz }\end{array}$ & $\begin{array}{l}\text { Spin-coating of propoxide precursor } \\
\text { solutions then heating at } 600^{\circ} \mathrm{C}, 6 \mathrm{~h}, 3 \\
\text { layers (Ti:Ir }=10: 1 \text { ) }\end{array}$ & 180 & - \\
\hline
\end{tabular}

a) Charge is stated only if thickness was controlled during synthesis

b) For transparent materials in $\mathrm{pH} 7$ phosphate buffer. Cathodic charge storage capacity range.

Insulating materials, such as glass, $\mathrm{TiO}_{2}$ and ( $\left.\mathrm{Ir}-\mathrm{Ti}\right) \mathrm{Ox}$ have no conductivity or charge storage capacity. ITO redox processes decompose the phase so its characterization is not included. Order of Impedance at low frequencies ${ }^{[7]}$ : IrOx $<$ PEDOT -PSS $<$ PEDOT-PPYamino acids $<$ Pt. Order of impedance at high frequencies ${ }^{[7]}$ : PEDOT-PPY-amino acids $<$ PEDOT-PSS $<$ IrOx $<$ Pt. 


\section{WILEY-VCH}

\section{Neuron growth and behaviour on prepared materials}

The neuronal growth and behavioural growth cone responses are summarised for conditions without electrical stimulation (Figure S1) and with stimulation at $50 \mathrm{mV} \mathrm{mm}^{-1}$

(Figure S2). Methods for growth and assessment were identical to those described in the main paper.
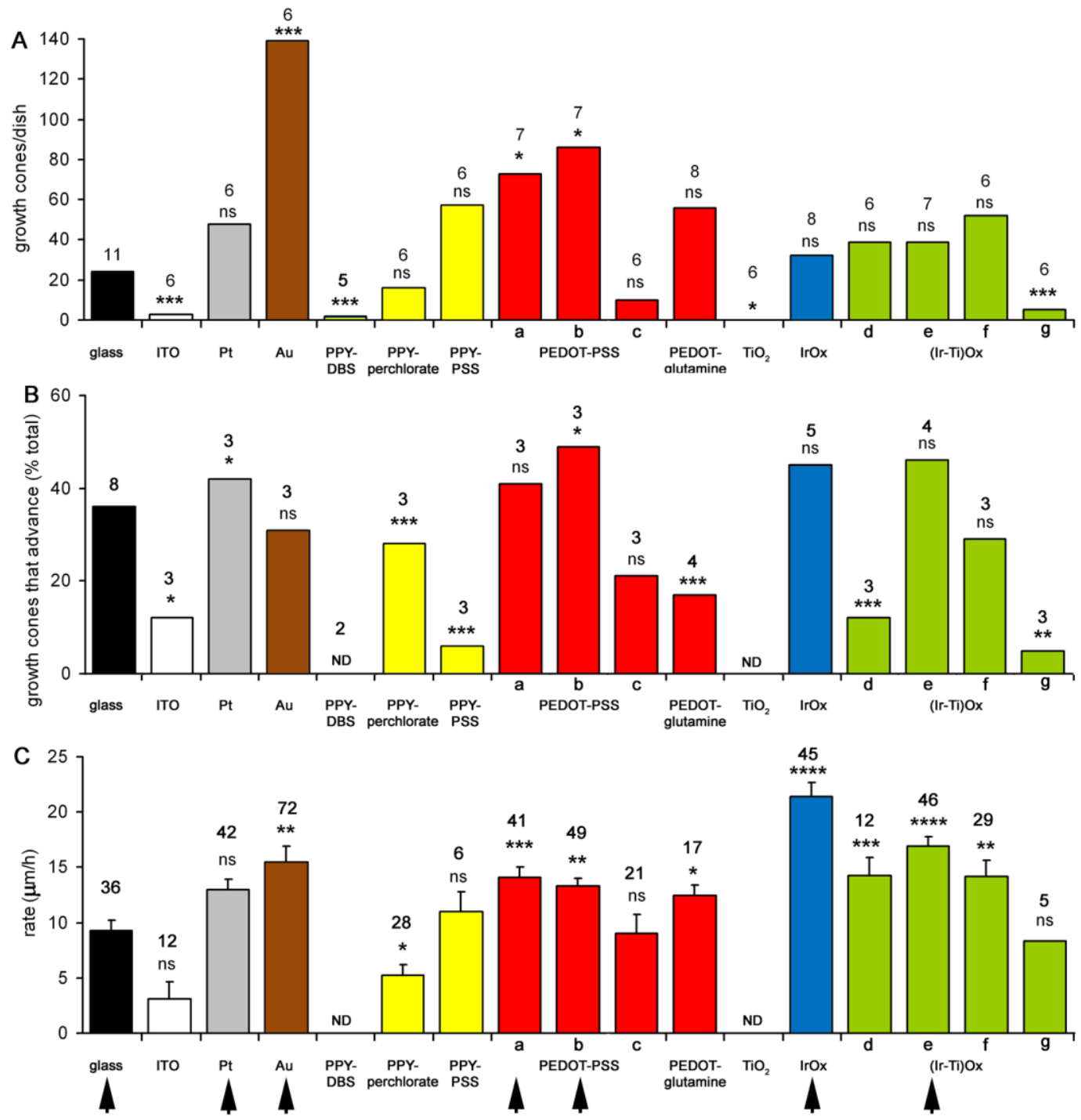

Figure S1. Neuron growth without stimulation. A) Number of growth cones per dish $6 \mathrm{~h}$ after plating. Number of dishes is shown. B) The percentage of growth cones that advanced continuously during $3 \mathrm{~h}$. Number of days experiment was repeated is shown. C) Rates of growth cone advance \pm SEM (Student's 2-tailed t). Number of growth cones is shown. Statistics compare to glass: $* \mathrm{p}<0.05, * * \mathrm{p}<0.005, * * * \mathrm{p}<0.001, * * * * \mathrm{p}<0.0001, \mathrm{~ns}=\mathrm{no}$ 


\section{WILEY-VCH}

significant difference, $\mathrm{ND}=$ not determined due to poor growth. The data presented in the main paper (arrows) are repeated here for ease of comparison.
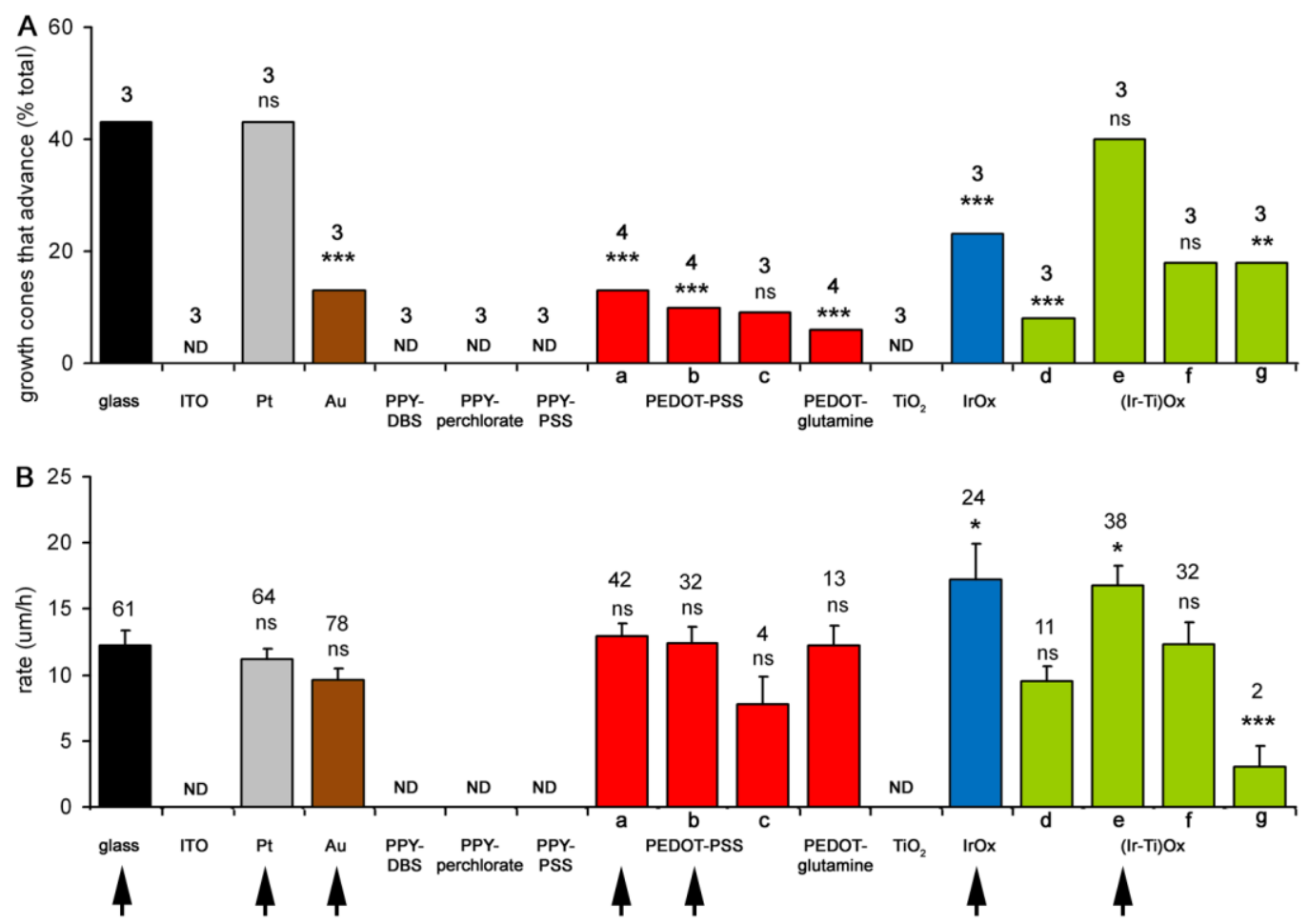

Figure S2. Neuron growth during $3 \mathrm{~h}$ of exposure to an imposed electric field of $50 \mathrm{mV} \mathrm{mm} \mathrm{m}^{-1}$.

A) Frequency of growth cones that advance. Number of dishes is shown. B) Growth rate ( \pm sem) (Student's 2 tailed t). Statistics compare to glass: $* \mathrm{p}<0.05, * * \mathrm{p}<0.005, * * * \mathrm{p}<$ $0.001, \mathrm{~ns}=$ no significant difference, $\mathrm{ND}=$ not determined due to poor growth . The data for substrates presented in the main paper are repeated here for ease of comparison (arrows).

\section{Supporting Information References}

[1] a) AM Cruz, Ll Abad, NM Carretero, J Moral-Vico, J Fraxedas, P Lozano, G Subias, V Padial, M Carballo, JE Collazos-Castro, N Casañ-Pastor, J Phys Chem C 2012, 116, 5155; b) MA Petit, V Plinchon, $J$ Electroanal Chem 1998, 444, 247; c) JE Bauer, TW Spaine, $J$. Electroanal Chem 1998, 443,208.

[2] KK Kasem, S Jones, Platinum Met Rev 2008, 52, 100. 


\section{WILEY-VCH}

[3] JE Collazos-Castro, AM Cruz, M Carballo-Vila, M Lira-Cantu, L Abad, A Perez del Pino,

J Fraxedas, A San Juan, C Fonseca, N Casan-Pastor, Thin Solid Films 2009, 518, 160.

[4] AM Cruz, N Casañ-Pastor, Thin Solid Films 2013, 534, 316.

[5] J Moral-Vico, NM Carretero, E Perez, C Suñol, M Lichtenstein, N Casañ-Pastor, Electrochim Acta 2013, 111, 250.

[6] J. Moral-Vico, PhD Thesis, CSIC, Universidad Autónoma de Barcelona, Spain 2012 , http://www.tdx.cat/handle/10803/402490.

[7] M.P. Lichtenstein, E. Pérez, L. Ballesteros, C. Suñol, N. Casañ-Pastor, Appl Mater Today 2017, 6, 29. 


\section{Click here to access/download \\ Supporting Information \\ Rajniek et al ADV HC Mat-supporting info revision.doc}


Click here to access/download

Production Data

Figure_1.tif 
Click here to access/download

Production Data

Figure_1A.tif 
Click here to access/download

Production Data

Figure_1B.tif 
Click here to access/download

Production Data

Figure_1C.tif 
Click here to access/download

Production Data

Figure_1D.tif 
Click here to access/download

Production Data

Figure_2A.tif 
Click here to access/download

Production Data

Figure_2B.tif 
Click here to access/download

Production Data

Figure_2C.tif 
Click here to access/download

Production Data

Figure_3.tif 
Click here to access/download

Production Data

Figure_3A.tif 
Click here to access/download

Production Data

Figure_3B.tif 
Click here to access/download

Production Data

Figure_3C.tif 
Click here to access/download

Production Data

Figure_3D.tif 
Click here to access/download

Production Data

Figure_4.tif 
Click here to access/download

Production Data

Figure_4A.tif 
Click here to access/download

Production Data

Figure_4B.tif 
Click here to access/download

Production Data

Figure_4C.tif 
Click here to access/download

Production Data

Figure_4D.tif 
Click here to access/download

Production Data

Figure_5.tif 
Click here to access/download

Production Data

Figure_5A.tif 
Click here to access/download

Production Data

Figure_5B.tif 
Click here to access/download

Production Data

Figure_5C.tif 
Click here to access/download

Production Data

Figure_5D.tif 
Click here to access/download

Production Data

Figure_6.tif 
Click here to access/download

Production Data

Figure_6A.tif 
Click here to access/download

Production Data

Figure_6B.tif 
Click here to access/download

Production Data

Figure_7.tif 
Click here to access/download

Production Data

Figure_7A.tif 
Click here to access/download

Production Data

Figure_7B.tif 
Click here to access/download

Production Data

Figure_7C.tif 
Click here to access/download

Production Data

ToC figure.tif 